Article

\title{
Synthetic Development of New 3-(4-Arylmethylamino)butyl-5- arylidene-rhodanines under Microwave Irradiation and Their Effects on Tumor Cell Lines and against Protein Kinases
}

\author{
Camille Déliko Dago ${ }^{1,2}$, Christelle N'ta Ambeu ${ }^{1,2}$, Wacothon-Karime Coulibaly ${ }^{3}$, \\ Yves-Alain Békro ${ }^{2}$, Janat Mamyrbékova ${ }^{2}$, Audrey Defontaine ${ }^{4}$, Blandine Baratte ${ }^{4}$, \\ Stéphane Bach ${ }^{4}$, Sandrine Ruchaud ${ }^{4}$, Rémy Le Guével ${ }^{5}$, Myriam Ravache ${ }^{5}$, Anne Corlu ${ }^{5}$ \\ and Jean-Pierre Bazureau ${ }^{1, *}$
}

1 Université de Rennes 1, Institut des Sciences Chimiques de Rennes (ISCR), UMR CNRS 6226, Groupe ICMV, Bât. 10A, Campus de Beaulieu, 263 Avenue du Général Leclerc, CS 74205, 35042 Rennes Cedex, France; E-Mails: deliko.dago@univ-rennes1.fr (C.D.D.); christelle.ambeu@univ-rennes1.fr (C.N.A.)

2 Laboratoire de Chimie Bio-Organique et de Substances Naturelles (LCBOSN), Université Nangui Abrogoua, Abidjan 02, BP 802, Cote d'Ivoire; E-Mails: bekro2001@yahoo.fr (Y.-A.B.); kojanova1926@hotmail.fr (J.M.)

3 UFR des Sciences Biologiques, Université de Péléforo Gon Coulibaly, Korhogo, BP 1328, Cote d'Ivoire; E-Mail: wacothon@yahoo.fr

4 Station Biologique de Roscoff, USR 3151, CNRS-UPMC, Kinase Inhibitory Specialized Screening facility, KISSf, Place George Teissier, BP 74, 29682 Roscoff, France; E-Mails: audrey.defontaine@sb-roscoff.fr (A.D.); blandine.baratte@sb-roscoff.fr (B.B.); stephane.bach@sb-roscoff.fr (S.B.); sandrine.ruchaud@sb-roscoff.fr (S.R.)

5 Université de Rennes 1, ImPACcell, SFR Biosit, Bât. 8, 2 Avenue du Professeur Léon Bernard, CS 34317, 35043 Rennes Cedex, France; E-Mails: remy.leguevel@univ-rennes1.fr (R.L.G.); myriam.ravache@gmail.com (M.R.); anne.corlu@univ-rennes1.fr (A.C.)

* Author to whom correspondence should be addressed;

E-Mail: jean-pierre.bazureau@univ-rennes1.fr; Tel.: +33-223-236-603; Fax: +33-223-236-374.

Academic Editor: Marilena Radoiu

Received: 27 May 2015 / Accepted: 30 June 2015 / Published: 8 July 2015

Abstract: A new route to 3-(4-arylmethylamino)butyl-5-arylidene-2-thioxo-1,3-thiazolidine-
4-one 9 was developed in six steps from commercial 1,4-diaminobutane $\mathbf{1}$ as starting
material. The key step of this multi-step synthesis involved a solution phase "one-pot 
two-steps" approach assisted by microwave dielectric from $N$-(arylmethyl)butane-1,4-diamine hydrochloride 6a-f (as source of the first point diversity) and commercial bis-(carboxymethyl)trithiocarbonate reagent 7 for construction of the rhodanine platform. This platform was immediately functionalized by Knoevenagel condensation under microwave irradiation with a series of aromatic aldehydes $\mathbf{3}$ as second point of diversity. These new compounds were prepared in moderate to good yields and the fourteen synthetic products $9 \mathbf{a}-\mathbf{n}$ have been obtained with a $Z$-geometry about their exocyclic double bond. These new 5-arylidene rhodanines derivatives $\mathbf{9 a}-\mathbf{n}$ were tested for their kinase inhibitory potencies against four protein kinases: Human cyclin-dependent kinase 5-p25, HsCDK5-p25; porcine Glycogen Synthase Kinase-3, GSK-3 $\alpha / \beta$; porcine Casein Kinase 1, SsCK1 and human HsHaspin. They have also been evaluated for their in vitro inhibition of cell proliferation (HuH7 D12, Caco 2, MDA-MB 231, HCT 116, PC3, NCI-H727, HaCat and fibroblasts). Among of all these compounds, 9j presented selective micromolar inhibition activity on $S s C K 1$ and $\mathbf{9 i}$ exhibited antitumor activities in the HuH7 D12, MDA-MBD231 cell lines.

Keywords: one-pot two-steps; Knoevenagel condensation; 5-arylidene rhodanine; protein kinase; inhibitor; $S_{s} \mathrm{CK} 1$; HsCDK5-p25; cell lines; Alzheimer's disease; cancer

\section{Introduction}

During the last decades, the five-membered heterocycle rings (FMHRs) are considered "privileged scaffolds" in medicinal chemistry [1]. Among the five-membered heterocycle rings, the 5-arylidene-2thioxo-1,3-thiazolidine-4-ones or 5-arylidene rhodanine derivatives represented particularly privileged moieties in drug discovery because they have an inherent tendency for biological activity [2], such as DDX3 inhibitor for HIV replication [3], as potent and selective inhibitors of the "atypical" dual-specificity phosphatase (DSP) family member-JNK-stimulating phosphatase-1 (JSP-1) [4], as pancreatic cholesterol esterase (CEase) inhibitor [5] with $\mathrm{IC}_{50}$ values ranging from 1.44 to $85 \mu \mathrm{M}$. To discover chemical probes to further understand the function of human DNA polymerase $\lambda$ in cancer, an inhibitor high-throughput screening (HTS) using SYBR $^{\circledR}$ Green-base assay [6] revealed that three 5-arylidene-2-thioxo1,3-thiazolidine-4-ones were identified as strong inhibitors. A new series of D-glutamic acid-base Escherichia coli MurD inhibitors incorporating the 5-arylidene rhodanine scaffold have been designed, synthesized and evaluated [7]. Substituted 5-arylidene-2-thioxo-1,3-thiazolidine-4-ones were able to inhibit HIV replication in MT-4 cells at low micromolar concentration with an appreciable selectivity index and are good scaffolds for the development of novel HIV-1 integrase inhibitors [8]. Recently, a family of 5-arylalkylidene rhodanine derivatives presented antiviral activity against chikungunya virus (LR2006_OPY1) in Vero cell culture by cytopathic effect CPE reduction assay [9]. For Alzheimer's disease, the FMHRs derived from 5-arylidene-2-thioxo-1,3-thiazolidine-4-ones have been described for amyloid polypeptide fibril formation [10], regulation of Cathepsin D immuno-reactivity in the senile plaques [11] and inhibition of tau aggregation [12].

Protein kinases represent an important class of enzymes that play an important role in the regulation of various processes. These enzymes catalyze protein-phosphorylation on serine, threonine and tyrosine 
residues, which are frequently deregulated in human diseases. Only the 518 human kinases have been investigated as potential therapeutic targets [13]. Consequently, the search of protein-kinase inhibitors represented interesting targets in the pharmaceutical industry for new therapeutic agents. Over the past decade, our research group have investigated the chemical development of five-membered heterocycle rings derived from marine alkaloid as low-molecular weight-inhibitors of dual specificity, tyrosine phosphorylation-regulated kinases (DYRKs) and CLKs (cdc2-like kinases) [14-16], two families of kinases involved in various diseases including Alzheimer's disease (AD) [17], and also cancer [18-20].

Continuing in the effort to identify new DYRK inhibitors, particularly DYRK1A, we continued to explore successively the synthesis of $N, N^{\prime}$-bis-(5-arylidene-4-oxo-3,5-dihydro- $4 H$-imidazol-2-yl) diamines [21], $N, N^{\prime}$-bis-(5-arylidene-4-oxo-4,5-dihydrothiazolidine-2-yl)aminopropylpiperazines [22] and finally unsymmetrical linked bis-5-arylidene-rhodanine derivatives linked in $N-3$ position [23] as potential kinases inhibitors (Figure 1). Among the three series of symmetrical or unsymmetrical $N, N^{\prime}$-diamines bearing various platforms (imidazolidine-4-one or 2-thioxo-1,3-thiazolidine-4-one moieties), only one of these compounds has shown nanomolar inhibition potency (IC50 $40 \mathrm{nM}$ ) towards DYRK1A. Owing to the fact that none of the unsymmetrical linked bis-5-arylidene rhodanines presented a significant activity against representative tumoral cell lines, we decided to change one of the two heterocyclic platforms by various (arylmethyl)aminobutyl moieties grafted on $N-3$ position of 5-arylidene-rhodanine derivatives in order to obtain significant potential biological activities on tumoral cell lines and effects on some protein kinases (HsCDK5-p25, SsGSK3 $\alpha / \beta, S s \mathrm{CK} 1$ and $H s$ Haspin). Herein, we present the building of this 3-(4-arylmethylamino)butyl-5-arylidene-rhodanine library in which the 5-arylidene-2-thioxo-1,3thiazolidine-4-one moiety was mostly carried out under microwave irradiation [24] and the biological activities of these compounds.
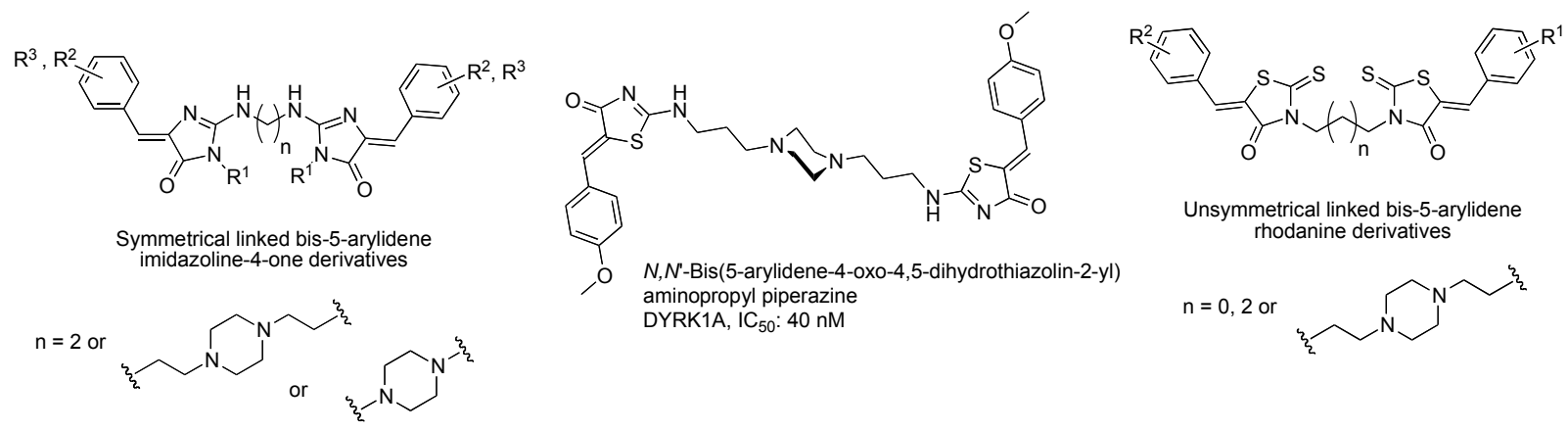

Figure 1. Symmetrical linked bis-5-arylidene imidazoline-4-ones, symmetrical linked bis-5-arylidene-1,3-thiazoline-4-ones and unsymmetrical linked bis-5-arylidene rhodanines derivatives (as inhibitors of the proteine kinase DYRK1A or against cell proliferation on cell tumor lines) identified and developed in our group.

\section{Results and Discussion}

\subsection{Chemistry}

Access to the planned 3-(4-arylphenylamino)butyl-5-arylidene-2-thioxo-1,3-thiazolidine-4-ones 9 is outlined in Scheme 1. For this study, we selected a diamino linker 1 with a butyl chain in order to obtain a good molecular flexibility between the 4-arylmethyl moiety and the 2-thioxo-1,3-thiazolidine-4-one 
platform. A molecule with the lowest number of carbons for the diamino linker is more conformationally restrained [25]. The 1,4-diamino-butane linker 1 was treated with di-tert-butyldicarbonate $\left(\mathrm{Boc}_{2} \mathrm{O}\right)$ in 1,4-dioxane at room temperature to afford mainly the mono- $N$-Boc protected amine $\mathbf{2}$ in good yield $(84 \%)$ [26]. To obtain a sufficient number of compounds suitable for a preliminary biological screening, we privileged the transformation of $N$-Boc-1,4-diamino-butane 2 into mono protected $N$-arylmethyl diamine 5 by reductive amination in two steps. The (4-arylmethylamino)butyl chain appended on the $N-3$ position of the 2-thioxo-1,3-thiazolidine-4-one platform represent the first point of diversity for the desired target compounds $\mathbf{9}$. Preparation of $\mathbf{4}$ was easily realized by reaction between of appropriate arylaldehyde $\mathbf{3 a}-\mathbf{f}$ with $N$-Boc diamine $\mathbf{2}$ in the presence of molecular sieves $3 \AA$ and, the condensation was conducted in a solution of diethyl ether $\mathrm{Et}_{2} \mathrm{O}$ at room temperature during $24 \mathrm{~h}$. Then, transformation of arylaldimines 4 into mono protected $N$-arylmethyl diamines 5 could be readily accomplished in good yields ( $85 \%$ to $98 \%$ ) using $\mathrm{NaBH}_{4}$ (5 equiv.) in $\mathrm{MeOH}$ at $50{ }^{\circ} \mathrm{C}$ during $24 \mathrm{~h}$. For the cleavage of $N$-Boc group, the use of trifluoroacetic acid in dichloromethane is often efficient, but in our case, we observed the formation of impurities resulting from uncontrolled degradation of 5 in this strong acidic media. We thus preferred to use a more classical and practical approach by using a solution of $6 \mathrm{M} \mathrm{HCl}$. The deprotection was conducted in 1,4-dioxane at room temperature after $4 \mathrm{~h}$ of reaction time. As can be seen from the data presented in Table 1, the $N$-(arylmethyl)butane-1,4-diamine hydrochloride 6a-f were efficiently prepared with electron-rich and electron-poor aldehydes $\mathbf{3 a}-\mathbf{f}$ in yields ranging from $72 \%$ to $98 \%$.

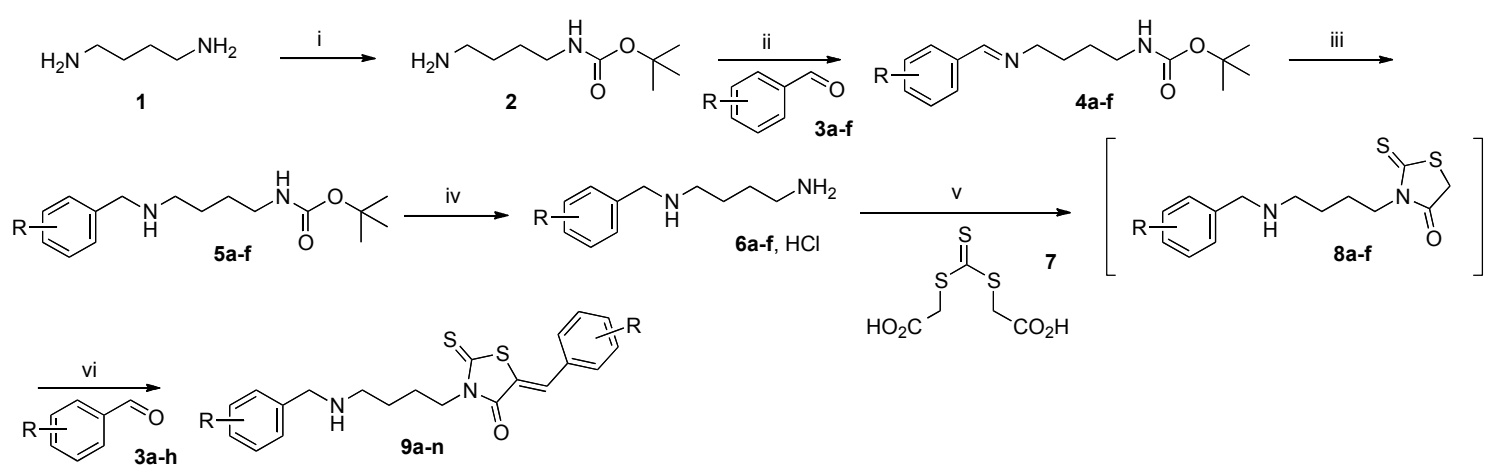

Scheme 1. Route used for the preparation of 3-(4-arylphenylamino)butyl-5-arylidene-2thioxo-1,3-thiazolidine-4-ones 9 via the "one-pot two-steps" reaction under microwave. Reagents and reaction conditions: (i) $\left(t-\mathrm{BuO}_{2} \mathrm{C}\right)_{2} \mathrm{O}, 1,4$-dioxane, $25{ }^{\circ} \mathrm{C}, 24 \mathrm{~h}$. (ii) 31 equiv., molecular sieve $3 \AA$, $\mathrm{Et}_{2} \mathrm{O}, 25^{\circ} \mathrm{C}, 16 \mathrm{~h}$. (iii) $\mathrm{NaBH}_{4} 5$ equiv., $\mathrm{MeOH}, 50{ }^{\circ} \mathrm{C}, 24 \mathrm{~h}$. (iv) $\mathrm{HCl} 6 \mathrm{M}, 1$,4-dioxane, $25^{\circ} \mathrm{C}, 4$ h. (v) 61 equiv., 71 equiv., Et $3 \mathrm{~N} 2$ or 3 equiv., DME, MWI, $90^{\circ} \mathrm{C}, 15$ or $30 \mathrm{~min}$. (vi) 31 equiv., MWI, $110^{\circ} \mathrm{C}, 15$ or $30 \mathrm{~min}$.

With the desired salts 6 in hand, we wished to examine the construction of the 2-thioxo-1,3thiazolidine-4-one platform followed by Knoevenagel condensation using arylaldehyde $\mathbf{3}$ under microwave irradiation for installation of the 5-arylidene moiety. The choice of arylaldehydes $\mathbf{3}$ in Knoevenagel condensation represent, in fact, the second point of diversity in the final structure of the targeted compounds 9. In a previous work issued from our laboratory [23], we have developed a "one-pot two-steps" method under microwave irradiation, which was applied for the synthesis of unsymmetrical linked bis-arylidene rhodanines from symmetric diamines. 
Table 1. Results for the preparation of compounds $2,4,5,6$ and 9.

\begin{tabular}{|c|c|c|c|c|c|c|}
\hline \multirow[b]{2}{*}{ Compound } & \multirow{2}{*}{$\begin{array}{l}\text { Starting } \\
\text { Product }\end{array}$} & \multicolumn{4}{|c|}{ 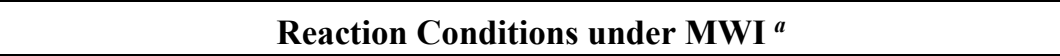 } & \multirow{2}{*}{$\begin{array}{r}\text { Yield }^{b} \\
(\%)\end{array}$} \\
\hline & & $\begin{array}{c}\text { Starting } \\
\text { Product } 6\end{array}$ & $\begin{array}{c}\text { Number of } \\
\text { equiv. for } \mathrm{Et}_{3} \mathrm{~N}\end{array}$ & $\begin{array}{l}\text { Reaction Time } \\
\text { for } 8^{c}(\min )\end{array}$ & $\begin{array}{l}\text { Reaction Time for } \\
\text { Condensation }^{d}(\mathrm{~min})\end{array}$ & \\
\hline 2 & - & - & - & - & - & 84 \\
\hline $4 a$ & 3a & - & - & - & - & 97 \\
\hline $4 b$ & $3 \mathbf{b}$ & - & - & - & - & 99 \\
\hline $4 c$ & $3 c$ & - & - & - & - & 98 \\
\hline 4d & 3d & - & - & - & - & 98 \\
\hline $4 e$ & $3 e$ & - & - & - & - & 98 \\
\hline $4 f$ & 3f & - & - & - & - & 99 \\
\hline $5 \mathbf{a}$ & $4 a$ & - & - & - & - & 93 \\
\hline $\mathbf{5 b}$ & $4 b$ & - & - & - & - & 99 \\
\hline $5 c$ & $4 c$ & - & - & - & - & 85 \\
\hline $5 d$ & $4 c$ & - & - & - & - & 90 \\
\hline $5 e$ & $4 e$ & - & - & - & - & 97 \\
\hline $5 f$ & $4 f$ & - & - & - & - & 98 \\
\hline $6 a$ & $5 a$ & - & - & - & - & 84 \\
\hline $6 b$ & $5 b$ & - & - & - & - & 97 \\
\hline $6 c$ & $5 c$ & - & - & - & - & 98 \\
\hline $6 d$ & $5 d$ & - & - & - & - & 98 \\
\hline $6 e$ & $5 e$ & - & - & - & - & 72 \\
\hline $6 f$ & $5 f$ & - & - & - & - & 92 \\
\hline 9a & $3 e$ & $6 \mathbf{b}$ & 3 & 30 & 30 & 10 \\
\hline $9 \mathrm{~b}$ & $3 b$ & $6 b$ & 3 & 30 & 30 & 6 \\
\hline $9 \mathrm{c}$ & 3f & $\mathbf{6 b}$ & 3 & 30 & 30 & 5 \\
\hline 9d & $3 \mathrm{~g}$ & $6 b$ & 3 & 30 & 30 & 30 \\
\hline $9 e$ & $3 e$ & 6d & 3 & 15 & 15 & 21 \\
\hline 9f & $3 f$ & 6d & 3 & 15 & 15 & 9 \\
\hline 9g & $3 d$ & 6d & 3 & 30 & 30 & 5 \\
\hline $9 \mathrm{~h}$ & $3 e$ & $6 e$ & 2 & 15 & 15 & 59 \\
\hline $9 \mathrm{i}$ & 3f & $6 e$ & 2 & 15 & 15 & 59 \\
\hline $9 \mathbf{j}$ & $3 h$ & $6 e$ & 2 & 15 & 15 & 34 \\
\hline 9k & $3 g$ & $6 e$ & 3 & 30 & 30 & 46 \\
\hline 91 & $3 e$ & $6 f$ & 3 & 15 & 15 & 15 \\
\hline $9 m$ & 3f & $6 f$ & 3 & 15 & 15 & 7 \\
\hline $9 n$ & $3 \mathrm{~g}$ & $6 f$ & 3 & 30 & 30 & 34 \\
\hline
\end{tabular}

Notes: ${ }^{a}$ Reaction realized in a tube (sealed with a snap cap) under microwave irradiation $(\mu \omega)$ with the Monowave ${ }^{\circledR} 300$ Anton-Paar reactor. ${ }^{b}$ Isolated yield. ${ }^{c}$ Reaction temperature: $90{ }^{\circ} \mathrm{C}$ for the preparation of 8 (1st period of microwave irradiation). ${ }^{d}$ Reaction temperature: $110^{\circ} \mathrm{C}$ for condensation reaction after addition of $\mathbf{3}$ (2nd period of microwave irradiation).

Application of this methodology, based on a "modified Holmberg method", first involved, in our case, the reaction of the commercial bis-(carboxymethyl)-trithiocarbonate reagent 7 with the synthesized 
$N$-(arylmethyl)butane-1,4-diamine hydrochloride $\mathbf{6}$ to afford the intermediate $\mathbf{8}$ and secondly, Knoevenagel condensation to produce the desired 5-arylidene rhodanines 9. This "one-pot two-steps" methodology was realized under microwave dielectric heating because the use of commercial scientific laboratory microwave apparatus favoured higher product yields and significant rate enhancements compared to reactions which run with conventional heating (i.e., in oil bath) [27]. After several experiments, optimal reaction conditions for this "one-pot two-steps" synthesis involved reaction of a stoichiometric mixture of $N$-(arylmethyl)butane-1,4-diamine hydrochloride 6 and commercial reagent 7 solubilized in dimethoxyethane with one or two equivalents of triethylamine. This starting reaction mixture was placed in a commercial glass tube closed with a snap cap and was irradiated with appropriate reaction time (15 or $30 \mathrm{~min}$.) at $90{ }^{\circ} \mathrm{C}$. After this first period of microwave irradiation followed by a cooling down to room temperature, aromatic aldehyde $\mathbf{3}$ was directly added to the crude suspension and was submitted again to microwave dielectric heating at $110{ }^{\circ} \mathrm{C}$ during 15 or $30 \mathrm{~min}$ for condensation.

The desired compound 9 was obtained as precipitate after addition of methanol in the solventless crude reaction mixture (after elimination of the volatile compounds in vacuo) and triturated, followed by successive washings with deionized water, ethanol, ether and finally was recrystallized from absolute EtOH to increase the quality of the precipitated product 9. A set of 14 pure compounds 9a-n was prepared in 5\%-59\% yield (Table 1) and all the products 9 were characterized by ${ }^{1} \mathrm{H}-,{ }^{13} \mathrm{C}-\mathrm{NMR}$ and HRMS before entering the biological tests. For the exocyclic double bond $(\mathrm{CH}=\mathrm{C})$ in $\mathrm{C}-5$ position of all the 3-(4-arylmethylamino)butyl-2-thioxo-1,3-thiazolidine-4-one 9a-n, it's possible in theory to observe $E$ - and/or Z-geometrical isomers. Examination of their ${ }^{1} \mathrm{H}-\mathrm{NMR}$ spectra in DMSO- $d_{6}$ showed only one signal for the methylene proton $(\mathrm{CH}=)$ in the range $7.54-7.74 \mathrm{ppm}$ at lower field values than those expected for the $E$-isomers, which indicates that all the compounds $9 \mathbf{a}-\mathbf{n}$ have the $Z$-configuration due to the high degree of thermodynamic stability of this isomer $[28,29]$. In ${ }^{13} \mathrm{C}-\mathrm{NMR}$, the signal of $\mathrm{C}-5(\mathrm{C}=)$ appears in the range 120.0-127.5 ppm, and we also observed only one signal for the exocyclic methylene proton $\left(134.6<\delta_{\mathrm{CH}}=<135.9 \mathrm{ppm}\right)$ that confirmed the presence of only the Z-geometrical isomer for the targeted compounds $\mathbf{9 a}-\mathbf{n}$.

\subsection{Biology}

As an initial effort to investigate their in vitro bioactivity, the new synthesized 3-(4-arylmethylamino) butyl-2-thioxo-1,3-thiazolidine-4-one 9a-n and also their precursors $\mathbf{6 a}-\mathbf{f}$ were evaluated for their in vitro inhibition of cell proliferation. For this study, we used a panel of seven representative tumoral cell lines, namely HuH7 D12 (differential hepato cellular carcinoma), Caco 2 (differentiating colorectal adenocarcinoma), MDA-MBD231 (prostate carcinoma), HCT 116 (actively proliferating colorectal adenocarcinoma), PC3 (prostate carcinoma), NCI-H727 (lung carcinoma), HaCat keratinocyte and, diploid skin fibroblasts as normal cell lines for control. Roscovitine, Doxorubicine and Taxol were also used as positive controls and their $\mathrm{IC}_{50}$ values are compared with those obtained for compounds $\mathbf{6}$ and $\mathbf{9 .}$ Results of the in vitro antiproliferative data activity are reported in Table 2 . None of the $N$-(arylmethyl) butane-1,4-diamines hydrochloride $\mathbf{6 a}-\mathbf{f}$ presented a significant activity against the seven representative tumoral cell lines. For the other compounds $\mathbf{9}$, the most active compound was clearly $\mathbf{9 i}$ (Figure 2) and exhibited antitumor activities in the HuH7 D12, MDA-MBD231 and HaCat cell lines with IC50 values lower than $10 \mu \mathrm{M}$ (HuH7 D12 and MDA-MBD231: IC50 $9 \mu \mathrm{M}$ ) and did not inhibit the growth of normal 
fibroblasts $\left(\mathrm{IC}_{50}>25 \mu \mathrm{M}\right)$. In addition, compounds $\mathbf{9 d}, \mathbf{9 h}, \mathbf{9 j}$ and $\mathbf{9 n}$ presented moderate antitumor activities ( $\mathrm{IC}_{50} 10-17 \mu \mathrm{M}$ ) in all cell lines of the panel but without selectivity.

Table 2. Antiproliferative activity of compounds $\mathbf{6}(\mathbf{a}-\mathbf{e})$ and $\mathbf{9}(\mathbf{a}-\mathbf{n})$ on six representative tumor cell lines.

\begin{tabular}{|c|c|c|c|c|c|c|c|c|}
\hline \multirow{2}{*}{ Compound } & \multicolumn{8}{|c|}{$\%$ of Survival ${ }^{a}$ and $\mathrm{IC}_{50}(\mu \mathrm{M})$ of Selected Compounds ${ }^{b}$} \\
\hline & Huh7 D12 & Caco 2 & MDA-MB231 & HCT 116 & PC3 & NCI-H727 & HaCat & Fibroblasts \\
\hline 6a & 102 & 114 & 104 & 112 & 100 & 97 & 97 & 93 \\
\hline $6 \mathbf{b}$ & 107 & 114 & 100 & 112 & 100 & 86 & 106 & 100 \\
\hline $6 \mathbf{c}$ & 82 & 93 & 102 & 98 & 96 & 100 & 80 & 84 \\
\hline $6 d$ & 107 & 111 & 99 & 111 & 98 & 92 & 96 & 93 \\
\hline $6 e$ & 91 & 106 & 102 & 102 & 96 & 98 & 96 & 93 \\
\hline $6 f$ & 88 & 109 & 99 & 96 & 97 & 92 & 94 & 105 \\
\hline 9a & 85 & 109 & 100 & 109 & 92 & 104 & 103 & 104 \\
\hline $9 \mathrm{~b}$ & 105 & 108 & 97 & 102 & 99 & 90 & 104 & 167 \\
\hline $9 c$ & 88 & 93 & 92 & 97 & 97 & 95 & 101 & 102 \\
\hline 9d & $7(10)$ & $23(15)$ & $15(11)$ & $1(10)$ & $41(17)$ & $11(10)$ & $2(10)$ & $29(>25)$ \\
\hline $9 e$ & 74 & 97 & 97 & 99 & 85 & 102 & 86 & 122 \\
\hline $9 f$ & 102 & 110 & 98 & 113 & 98 & 96 & 100 & 134 \\
\hline $9 \mathrm{~g}$ & 111 & 117 & 104 & 118 & 98 & 95 & 110 & 100 \\
\hline $9 \mathrm{~h}$ & $7(10)$ & $42(14)$ & $49(10)$ & $65(13)$ & $51(13)$ & $43(>25)$ & $10(10)$ & $80(>25)$ \\
\hline $9 \mathrm{i}$ & $5(9)$ & $17(13)$ & $17(9)$ & $8(14)$ & $39(14)$ & $9(11)$ & $6(8)$ & $54(>25)$ \\
\hline $9 j$ & $22(11)$ & $41(27)$ & $42(19)$ & $40(22)$ & $38(19)$ & $33(19)$ & $21(13)$ & $77(>25)$ \\
\hline $9 k$ & 72 & 98 & 92 & 98 & 83 & 96 & 80 & 84 \\
\hline 9l & 90 & 105 & 98 & 106 & 93 & 96 & 95 & 128 \\
\hline $9 m$ & 97 & 107 & 99 & 103 & 96 & 98 & 94 & 149 \\
\hline $9 n$ & $41(15)$ & $28(16)$ & $55(15)$ & $52(21)$ & $61(19)$ & $63(17)$ & $48(15)$ & $86(>25)$ \\
\hline Roscovitine & $21(15)$ & $3(15)$ & $21(12$ & $10(9)$ & $24(13)$ & $30(43)$ & $6(11)$ & $53(125)$ \\
\hline Doxorubicine & $63(0.03)$ & $43(0.03)$ & $82(0.01)$ & $22(0.03)$ & 34 & 65 & $88(0.02)$ & $74(>0.25)$ \\
\hline Taxol & $36(0.003)$ & $29(0.04)$ & $41(0.04)$ & $9(<0.001)$ & $35(<0.001)$ & 59 & $11(0.001)$ & $76(>25)$ \\
\hline DMSO & $100(>25)$ & $100(>25)$ & $100(>25)$ & $100(>25)$ & $100(>25)$ & $100(>25)$ & $100(>25)$ & $100(>25)$ \\
\hline
\end{tabular}

Notes: ${ }^{a}$ Percentage of survival measured at $25 \mu \mathrm{M}$ (after $48 \mathrm{~h}$ using a single dose, triplicate). ${ }^{b} \mathrm{IC}_{50}$ values in brackets are expressed in $\mu \mathrm{M}$ and are the average of three assays, standard error $\pm 0.5 \mu \mathrm{M}$.
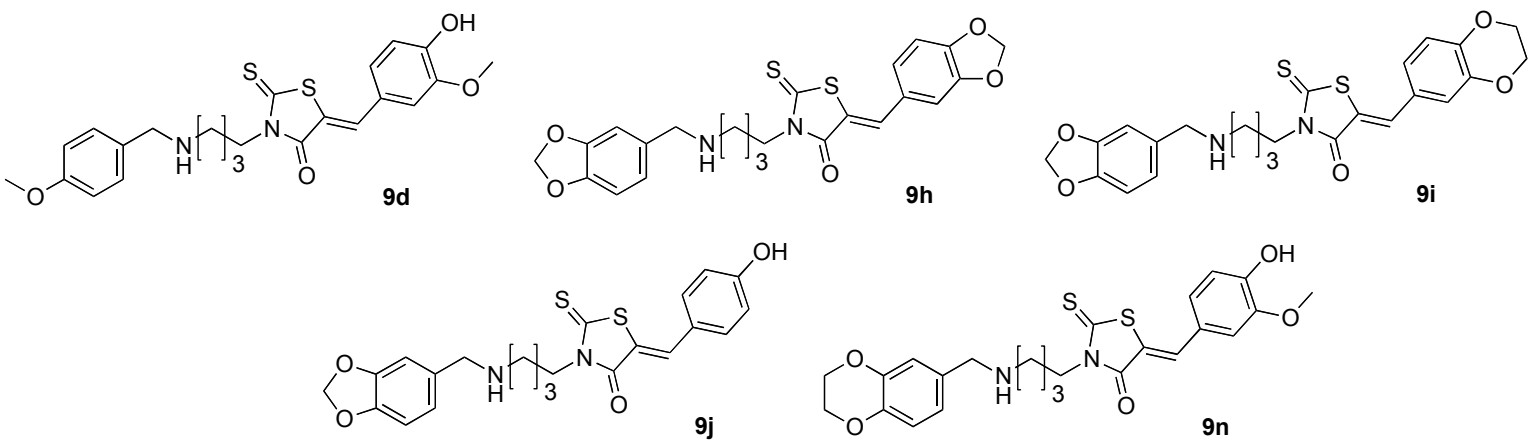

Figure 2. Structure of compounds $9 \mathbf{d}, \mathbf{9}(\mathbf{h}-\mathbf{j})$ and $\mathbf{9 n}$, which are active against protein kinases and/or tumor cell lines. 
Then, we evaluated the intermediates salts $\mathbf{6 a}-\mathbf{f}$ and fourteen final compounds $9 \mathbf{a}-\mathbf{n}$ on four protein kinases: HsCDK5-p25 (cyclin-dependant kinase 5-p25), SsGSK-3 $\alpha / \beta$ (glycogen synthase kinase-3 $\alpha / \beta$ ) $S s \mathrm{CK} 1 \delta / \varepsilon$ (Caseine kinase 1 ) and $H s$ Haspin as an essential mitotic kinase [30]. All assays were run in the presence of $15 \mu \mathrm{M}$ of ATP and appropriate substrates. IC 50 values were determined from dose-response curves. Concerning the library of the fourteen (5Z) 3-(4-arylmethylamino)butyl-5-arylidene-2-thioxo1,3-thiazolidine-4-ones 9a-n and also the six diamines salts $\mathbf{6 a}-\mathbf{f}$, the results are given in Table 3. Among all the products, the main part of their inhibition activity was focused on two proteins kinases ( $S s \mathrm{CK} 1$ and $H s C D K 5-\mathrm{p} 25)$ for four products, which exhibited inhibitory activity in the micromolar range (SsCK1: $1.4 \mu \mathrm{M}<\mathrm{IC}_{50}<6.6 \mu \mathrm{M}$; HsCDK5-p25: $\mathrm{IC}_{50} 1.2 \mu \mathrm{M}$ ). For the compound 9j and 9n, we observed micromolar inhibition activity on $S_{s C K} 1$ (IC 50 values for 9j: $1.4 \mu \mathrm{M}$ and 9n: $2 \mu \mathrm{M}$ ) with good selectivity. It is interesting to note that these two compounds are respectively substituted with an hydroxyl function on para-position of the 5-arylidene moiety and also with a similar bulky group (1,3-benzodioxol-5-yl for 9j and 2,3-dihydro-benzo[1,4]dioxin-6-yl for 9n) on the arylmethylamino moiety grafted on the $\mathrm{N}-3$ butyl chain. On the contrary, the presence of 1,3-benzodioxol-5-yl (for 9h) or 2,3-dihydro-benzo[1,4]dioxin-6-yl moiety (for 9i) in the 5-arylidene group induced a moderate loss of inhibition activity for $S_{s} \mathrm{CK} 1$ ( $\mathrm{IC}_{50}$ for $9 \mathrm{~h}: 6.6 \mu \mathrm{M}$ and $9 \mathrm{i}$ : $5.4 \mu \mathrm{M}$ ) associated with micromolar affinity for $H_{s} \mathrm{CDK} 5-\mathrm{p} 25$ ( $\mathrm{IC}_{50}$ for $9 \mathbf{h}: 1.1 \mu \mathrm{M}$ and $9 \mathbf{i}$ : $1.3 \mu \mathrm{M}$ ). Compound 9i presented also inhibition proliferation activity on Huh7 D12, MDA-MBD231 cell lines and is inactive against normal fibroblasts.

Table 3. Effects of the compounds $6 \mathbf{a}-\mathbf{f}$ and $9 \mathbf{a}-\mathbf{n}$ on the catalytic activity of four purified protein kinases ${ }^{a}$.

\begin{tabular}{|c|c|c|c|c|}
\hline Compound & HsCDK5/p25 & SsGSK-3 $\alpha / \beta$ & 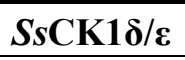 & HsHaspin \\
\hline $6 \mathbf{a}-\mathbf{f}$ & $>10$ & $>10$ & $>10$ & $>10$ \\
\hline $9 a-g$ & $>10$ & $>10$ & $>10$ & $>10$ \\
\hline $9 \mathrm{~h}$ & 1.1 & $>10$ & 6.6 & $>10$ \\
\hline $9 \mathbf{i}$ & 1.3 & $>10$ & 5.1 & $>10$ \\
\hline $9 \mathbf{j}$ & $>10$ & $>10$ & 1.4 & $>10$ \\
\hline $9 \mathbf{k}-\mathbf{m}$ & $>10$ & $>10$ & $>10$ & $>10$ \\
\hline $9 n$ & 10 & $>10$ & 2 & $>10$ \\
\hline
\end{tabular}

Note: ${ }^{a}$ Compounds were tested at various concentrations on each kinase as described in Experimental Section. $\mathrm{IC}_{50}$ values, calculated from the dose-response curves, are reported in $\mu \mathrm{M}>10$, inhibitory but $\mathrm{IC}_{50}>10 \mu \mathrm{M}$.

\section{Experimental Section}

\subsection{Chemistry Section}

\subsubsection{General Section}

Melting points were determined on a Kofler melting point apparatus and were uncorrected. Thin-layer chromatography (TLC) was accomplished on 0.2-mm precoated plates of silica gel 60 F-254 (Merck, Fontenay-sous-Bois, France). Visualization was made with ultraviolet light (254 and $365 \mathrm{~nm}$ ) or with a fluorescence indicator. ${ }^{1} \mathrm{H}-\mathrm{NMR}$ spectra were recorded on BRUKER AC $300 \mathrm{P}$ (300 MHz) spectrometer, ${ }^{13} \mathrm{C}-\mathrm{NMR}$ spectra on a BRUKER AC $300 \mathrm{P}(75 \mathrm{MHz})$ spectrometer. Chemical shifts are expressed in parts per million downfield from tetramethylsilane as an internal standard. Data are given in the 
following order: $\delta$ value, multiplicity (s, singlet; d, doublet; t, triplet; q, quartet; m, multiplet; br, broad), number of protons, coupling constants $J$ is given in Hertz. The mass spectra (HRMS) were taken respectively on a MS/MS ZABSpec Tof Micromass (EBE TOF geometry) at an ionizing potential of $8 \mathrm{eV}$ and on a VARIAN MAT 311 at an ionizing potential of $70 \mathrm{eV}$ in the Centre Régional de Mesures Physiques de l'Ouest (CRMPO, Rennes, France). Reactions under microwave irradiations were realized in the Anton Paar Monowave $300^{\circledR}$ microwave reactor (Anton-Paar, Courtaboeuf, France) using borosilicate glass vials of $10 \mathrm{~mL}$ equipped with snap caps (at the end of the irradiation, cooling reaction was realized by compressed air). The microwave instrument consists of a continuous focused microwave power output from 0 to $800 \mathrm{~W}$ for this Monowave $300^{\circledR}$ apparatus. All the experiments in the microwave reactor were performed using a stirring option. The target temperature was reached with a ramp of 5 min and the chosen microwave power stayed constant to hold the mixture at this temperature. The reaction temperature is monitored using calibrated infrared sensor and the reaction time included the ramp period. The microwave irradiation parameters (power and temperature) were monitored by the Monowave software package of the Monowave $300^{\circledR}$ microwave reactor. Solvents were evaporated with a BUCHI rotary evaporator. All reagents and solvents were purchased from Acros, Sigma-Aldrich Chimie (Saint-Quentin Fallavier, France), TCI France and Fluka France and were used without further purification.

tert-Butyl (4-aminobutyl)carbamate (2). In a $250 \mathrm{~mL}$ two-necked round-bottomed flask, provided with magnetic stirrer and condenser, commercial 1,4-diaminobutane 1 (14.3 mL, $12.5 \mathrm{~g}, 0.14 \mathrm{~mol})$ was solubilized in $69 \mathrm{~mL}$ of 1,4-dioxane at room temperature. To this mixture was added dropwise a solution of commercial di-tert-butyldicarbonate $(6.5 \mathrm{~g}, 30 \mathrm{mmol})$ in 1,4-dioxane $(85 \mathrm{~mL})$ over a period of $3 \mathrm{~h}$. After vigorous stirring at $25{ }^{\circ} \mathrm{C}$ during a $12 \mathrm{~h}$ period, the volatile compounds of the reaction mixture were eliminated in vacuo and into the crude reaction mixture was poured $150 \mathrm{~mL}$ of deionized water. The mixture was extracted with methylene chloride $(5 \times 50 \mathrm{~mL})$, organic phases were collected and dried over magnesium sulfate. The filtrate was concentrated in a rotary evaporator under reduced pressure and was dried under high vacuum $\left(10^{-2}\right.$ Torr) at $25^{\circ} \mathrm{C}$ for $10 \mathrm{~min}$. The desired carbamate $2(1.58 \mathrm{~g})$ was obtained as a colourless mobile oil in $84 \%$ yield and was further used without purification. ${ }^{1} \mathrm{H}-\mathrm{NMR}$ $\left(\mathrm{DMSO}-d_{6}\right) \delta: 1.34$ (s, 9H, Me $\left.3 \mathrm{CO}\right) ; 1.40\left(\mathrm{~m}, 4 \mathrm{H}, \mathrm{CH}_{2}\right) ; 2.61$ (t, 2H, $\left.J=6.7 \mathrm{~Hz}, \mathrm{CH}_{2}\right) ; 3.02$ (m, 2H, $\mathrm{CH}_{2} \mathrm{NH}$ ); 4.93 (br s, 2H, $\mathrm{NH}_{2}$ ); 5.71 (br s, 1H, NH). ${ }^{13} \mathrm{C}-\mathrm{NMR}$ (DMSO-d6) $\delta: 27.2\left(\mathrm{CH}_{2}\right) ; 28.4$ $\left(\mathrm{OC}\left(\underline{\mathrm{CH}}_{3}\right)_{3}\right) ; 29.5\left(\mathrm{CH}_{2}\right) ; 40.2\left(\mathrm{CH}_{2}\right) ; 41.1\left(\mathrm{CH}_{2}\right) ; 78.9\left(\mathrm{OC}\left(\mathrm{CH}_{3}\right)_{3}\right) ; 156.1(\mathrm{C}=\mathrm{O}) . \mathrm{HRMS}, m / z$ : 189.1600 found (calculated for $\mathrm{C}_{9} \mathrm{H}_{21} \mathrm{~N}_{2} \mathrm{O}_{2}[\mathrm{M}+\mathrm{H}]^{+}$requires 189.1603).

\subsubsection{Standard Procedure for the Preparation of Aldimines 4a-f from tert-Butyl (4-aminobutyl) Carbamate $\mathbf{2}$ and Aromatic Aldehyde 3a-f}

In a $100 \mathrm{~mL}$ two-necked round-bottomed flask, provided with magnetic stirrer and condenser, containing a solution of tert-butyl (4-aminobutyl)carbamate $2(1.97 \mathrm{~g}, 10.5 \mathrm{mmol})$ in anhydrous ether $(50 \mathrm{~mL})$ was added dropwise during $30 \mathrm{~min}$, a suspension of commercial aldehyde (10 mmol) in anhydrous ether ( $30 \mathrm{~mL})$ and molecular sieves ( $2 \mathrm{~g}, 3 \AA, 8-12 \mathrm{mesh})$. The crude reaction mixture is stirred vigorously for $16 \mathrm{~h}$ at room temperature until the disappearance of aromatic aldehyde 3 controlled by thin-layer chromatography on 0.2-mm precoated plates of silica gel 60 F-254 (Merck). The crude reaction mixture 
was filtered on filter paper and then concentrated in a rotary evaporator under reduced pressure. The crude residue was dried under high vacuum $\left(10^{-2} \mathrm{Torr}\right)$ at $25^{\circ} \mathrm{C}$ for $10 \mathrm{~min}$. The desired aldimine 4 was obtained as yellowish viscous oil and was further used without purification.

[4-(Benzylidene-amino)-butyl]-carbamic acid tert-butyl ester (4a). Compound 4a was prepared in 97\% yield (2.68 g) from benzaldehyde 3a (1.06 g, $10 \mathrm{mmol})$ according to the standard procedure as yellowish viscous oil. ${ }^{1} \mathrm{H}-\mathrm{NMR}$ (DMSO- $\left.d_{6}\right) \delta: 1.37$ (s, 9H, Me $3 \mathrm{C}$ ); 1.40-1.48 (m, 2H, CH, $\left.\mathrm{H}-2\right)$; 1.54-1.62 (m, 2H, $\mathrm{CH}_{2}, \mathrm{H}-3$ ); 2.96 (q, 2H, $J=6.8 \mathrm{~Hz}, \mathrm{CH}_{2} \mathrm{NH}, \mathrm{H}-1$ ); 3.55 (t, 2H, $J=6.8 \mathrm{~Hz}, \mathrm{CH}_{2} \mathrm{~N}=, \mathrm{H}-4$ ); 6.79-6.83 (br s, 1H, NH); 7.41-7.46 (m, 3H, H-3', H-4', H-5', Ar); 7.71-7.75 (m, 2H, H-2', H-6', Ar); 8.32 (s, 1H, $\mathrm{N}=\mathrm{CH}) .{ }^{13} \mathrm{C}-\mathrm{NMR}\left(\mathrm{DMSO}-d_{6}\right) \delta: 27.3(\mathrm{C}-2) ; 27.8(\mathrm{C}-3) ; 28.2(\mathrm{OC}(\underline{\mathrm{CH}} 3) 3) ; 39.6(\mathrm{C}-1) ; 60.1$ (C-4); 77.2 $\left(\mathrm{O} \underline{(}\left(\mathrm{CH}_{3}\right) 3\right) ; 127.7$ (C-2', C-6', Ar); 128.5 (C-3', C-5', Ar); 130.4 (C-4', Ar); 136.1 (C-1', Ar); 155.5 $(\underline{\mathrm{C}}=\mathrm{O}) ; 160.5(\mathrm{~N}=\underline{\mathrm{C}} \mathrm{H})$.

\{4-[(4-Methoxy-benzylidene)-amino]-butyl\}-carbamic acid tert-butyl ester (4b). Compound $\mathbf{4 b}$ was prepared in 99\% yield (3.03 g) from 4-methoxybenzaldehyde $\mathbf{3 b}(1.36 \mathrm{~g}, 10 \mathrm{mmol})$ according to the standard procedure as yellowish viscous oil. ${ }^{1} \mathrm{H}-\mathrm{NMR}$ (DMSO- $\left.d_{6}\right) \delta: 1.37\left(\mathrm{~s}, 9 \mathrm{H}, \mathrm{Me}_{3} \mathrm{C}\right) ; 1.32-1.46$ (m, 2H, CH $2, \mathrm{H}-2)$; 1.52-1.61 (m, 2H, $\left.\mathrm{CH}_{2}, \mathrm{H}-3\right)$; 2.94 (q, 2H, J=6.9 Hz, $\left.\mathrm{CH}_{2} \mathrm{NH}, \mathrm{H}-1\right)$; 3.50 (t, 2H, $\left.J=6.8 \mathrm{~Hz}, \mathrm{CH}_{2} \mathrm{~N}=, \mathrm{H}-4\right) ; 3.80$ (s, 3H, $\left.\mathrm{OCH}_{3}\right) ; 6.77-6.82($ br s, $1 \mathrm{H}, \mathrm{NH}) ; 6.98$ (d, 2H, $J=8.8 \mathrm{~Hz}, \mathrm{H}-2^{\prime}$, H-6', Ar); 7.66 (d, 2H, J=8.8 Hz, H-3', H-5', Ar); 8.24 (s, 1H, N=CH). ${ }^{13} \mathrm{C}-\mathrm{NMR}$ (DMSO-d6) $\delta: 27.4$ $\left.\left.(\mathrm{C}-2) ; 28.0(\mathrm{C}-3) ; 28.2\left(\mathrm{OC}\left(\underline{\mathrm{C}} \mathrm{H}_{3}\right) 3\right) ; 39.6(\mathrm{C}-1) ; 55.2\left(\mathrm{OCH}_{3}\right) ; 60.1(\mathrm{C}-4) ; 77.3\left(\mathrm{OC}_{(\mathrm{CH}}\right)\right)_{3}\right) ; 114.0\left(\mathrm{C}-2^{\prime}\right.$, C-6', Ar); 129.0 (C-1', Ar); 129.3 (C-3', C-5', Ar); 155.5 ( $\underline{\mathrm{C}}=\mathrm{O}) ; 159.7(\mathrm{~N}=\underline{\mathrm{C}} \mathrm{H}) ; 161.0$ (C-4', Ar).

\{4-[(2-Chloro-benzylidene)-amino]-butyl\}-carbamic acid tert-butyl ester (4c). Compound $\mathbf{4 c}$ was prepared in 98\% yield (3.05 g) from 2-chlorobenzaldehyde $3 \mathbf{c}(1.41 \mathrm{~g}, 10 \mathrm{mmol})$ according to the standard procedure as yellowish viscous oil. ${ }^{1} \mathrm{H}-\mathrm{NMR}$ (DMSO-d6) $\delta: 1.37\left(\mathrm{~s}, 9 \mathrm{H}, \mathrm{Me}_{3} \mathrm{C}\right) ; 1.34-1.48$ (m, 2H, CH $2, \mathrm{H}-2)$; 1.56-1.63 (m, 2H, $\left.\mathrm{CH}_{2}, \mathrm{H}-3\right)$; 2.96 (q, 2H, J = 6.7 Hz, CH $\left.2 \mathrm{NH}, \mathrm{H}-1\right)$; 3.61 (t, 2H, $\left.J=6.8 \mathrm{~Hz}, \mathrm{CH}_{2} \mathrm{~N}=, \mathrm{H}-4\right) ; 6.78-6.82$ (br s, $\left.1 \mathrm{H}, \mathrm{NH}\right) ; 7.36-7.52$ (m, 3H, H-4', H-5', H-6', Ar); 7.94-7.97 (m, 1H, H-3', Ar); 8.65 (s, 1H, N=CH). ${ }^{13} \mathrm{C}-\mathrm{NMR}$ (DMSO-d6) $\delta: 27.3$ (C-2); 27.7 (C-3); 28.2 $\left(\mathrm{OC}\left(\underline{\mathrm{CH}}_{3}\right)_{3}\right) ; 39.6(\mathrm{C}-1) ; 60.4(\mathrm{C}-4) ; 77.2\left(\mathrm{OC}\left(\mathrm{CH}_{3}\right)_{3}\right) ; 127.4\left(\mathrm{C}-5^{\prime}, \mathrm{Ar}\right) ; 128.0\left(\mathrm{C}-4^{\prime}, \mathrm{Ar}\right) ; 129.8\left(\mathrm{C}-6^{\prime}\right.$, Ar); 132.0 (C-3', Ar); 132.7 (C-1', C-2', Ar); 133.8 (C-1', C-2', Ar); $155.5(\underline{\mathrm{C}}=\mathrm{O}) ; 156.6(\mathrm{~N}=\underline{\mathrm{C}} \mathrm{H})$.

\{4-[(3-Methoxy-benzylidene)-amino]-butyl\}-carbamic acid tert-butyl ester (4d). Compound 4d was prepared in 98\% yield (3.03 g) from 3-methoxybenzaldehyde 3d (1.36 g, $10 \mathrm{mmol})$ according to the standard procedure as yellowish viscous oil. ${ }^{1} \mathrm{H}-\mathrm{NMR}$ (DMSO-d6) $\delta: 1.37\left(\mathrm{~s}, 9 \mathrm{H}, \mathrm{Me}_{3} \mathrm{C}\right) ; 1.36-1.45$ (m, 2H, CH $2, \mathrm{H}-2)$; 1.54-1.64 (m, 2H, CH $2, \mathrm{H}-3)$; 2.96 (q, 2H, J = 6.7 Hz, CH $2 \mathrm{NH}, \mathrm{H}-1$ ); 3.54 (t, 2H, $\left.J=6.7 \mathrm{~Hz}, \mathrm{CH}_{2} \mathrm{~N}=, \mathrm{H}-4\right) ; 3.78$ (s, 3H, $\left.\mathrm{OCH}_{3}\right), 6.76-6.82$ (br s, 1H, NH); 6.99-7.03 (m, 1H, H-5', Ar); 7.27-7.38 (m, 3H, H-2', H-4', H-6', Ar); 8.29 (s, 1H, N=CH). ${ }^{13} \mathrm{C}-\mathrm{NMR}$ (DMSO-d6) $\delta: 27.3$ (C-2); 27.8 (C-3); $\left.28.2\left(\mathrm{OC}_{(\underline{\mathrm{CH}}}\right)_{3}\right) ; 39.6(\mathrm{C}-1) ; 55.0\left(\mathrm{O}_{\mathbf{C H}}\right)$ ); $60.1(\mathrm{C}-4) ; 77.2\left(\mathrm{OC}\left(\mathrm{CH}_{3}\right)_{3}\right) ; 111.9\left(\mathrm{C}-5^{\prime}, \mathrm{Ar}\right)$; 116.6 (C-6', Ar); 120.6 (C-4', Ar); 129.6 (C-2', Ar); 137.6 (C-1', Ar); 155.5 (C =O); 159.4 (C-3', Ar); $160.4(\underline{\mathrm{C}}=\mathrm{N})$.

\{4-[(Benzo[1,3]dioxol-5-ylmethylene)-amino]-butyl\}-carbamic acid tert-butyl ester (4e). Compound $\mathbf{4 e}$ was prepared in $98 \%$ yield $(3.13 \mathrm{~g})$ from 3,4-methylenedioxybenzaldehyde $3 \mathbf{e}(1.51 \mathrm{~g}, 10 \mathrm{mmol})$ 
according to the standard procedure as yellowish viscous oil. ${ }^{1} \mathrm{H}-\mathrm{NMR}$ (DMSO-d6) $\delta: 1.37$ (s, 9H, $\mathrm{Me}_{3} \mathrm{C}$ ); 1.30-1.46 (m, 2H, CH $\left.2, \mathrm{H}-2\right)$; 1.51-1.61 (m, 2H, CH $\left.2, \mathrm{H}-3\right) ; 2.94$ (q, 2H, J = 6.9 Hz, $\mathrm{CH}_{2} \mathrm{NH}$, $\mathrm{H}-1) ; 3.49$ (t, 2H, $\left.J=6.7 \mathrm{~Hz}, \mathrm{CH}_{2} \mathrm{~N}=, \mathrm{H}-4\right) ; 6.07$ (s, 2H, H-2', Ar), 6.77-6.82 (br s, 1H, NH); 6.97 (d, $1 \mathrm{H}, J=8 \mathrm{~Hz}, \mathrm{H}-6$ ', H-7', Ar); 7.16-7.20 (m, 1H, H-6', H-7', Ar); 7.27-7.28 (m, 1H, H-4', Ar), 8.20 (s, $1 \mathrm{H}, \mathrm{N}=\mathrm{CH}) .{ }^{13} \mathrm{C}-\mathrm{NMR}\left(\mathrm{DMSO}-d_{6}\right) \delta: 27.3(\mathrm{C}-2) ; 27.9$ (C-3); $28.2\left(\mathrm{OC}\left(\underline{\mathrm{CH}}_{3}\right) 3\right) ; 39.6$ (C-1); 59.8 (C-4); $77.4\left(\mathrm{O} \underline{\mathrm{C}}\left(\mathrm{CH}_{3}\right)_{3}\right) ; 101.4$ (C-2', Ar); 105.8 (C-6', Ar); 108.1 (C-7', Ar); 124.0 (C-4', Ar); 130.9 (C-5', Ar); 147.8 (C-3a', C-7a', Ar); $149.3\left(\mathrm{C}-3 \mathrm{a}^{\prime}, \mathrm{C}-7 \mathrm{a}^{\prime}, \mathrm{Ar}\right) ; 155.5(\underline{\mathrm{C}}=\mathrm{O}) ; 160.0(\underline{\mathrm{C}}=\mathrm{N})$.

\{4-[(2,3-Dihydro-benzo[1,4]dioxin-6-ylmethylene)-amino]-butyl\}-carbamic acid tert-butylester (4f). Compound $4 \mathbf{f}$ was prepared in $99 \%$ yield $(3.31 \mathrm{~g})$ from 2,3-dihydro-benzo[1,4]dioxin-6-carbaldehyde 3f $(1.50 \mathrm{~g}, 10 \mathrm{mmol})$ according to the standard procedure as yellowish viscous oil. ${ }^{1} \mathrm{H}-\mathrm{NMR}$ (DMSO-d6) $\delta$ : 1.37 (s, 9H, Me 3 C); 1.34-1.45 (m, 2H, CH $2, \mathrm{H}-2)$; 1.51-1.60 (m, 2H, CH2, H-3); 2.94 (q, 2H, $J=6.8 \mathrm{~Hz}$, $\left.\mathrm{CH}_{2} \mathrm{NH}, \mathrm{H}-1\right) ; 3.50$ (t, 2H, $\left.J=6.7 \mathrm{~Hz}, \mathrm{CH}_{2} \mathrm{~N}=, \mathrm{H}-4\right) ; 4.23-4.30$ (m, 4H, H-2', H-3', Ar), 6.77-6.81 (br s, 1H, NH); 6.88-6.91 (m, 1H, H-7', Ar); 7.18-7.21 (m, 2H, H-5', H-8', Ar); 8.17 (s, 1H, N=CH).

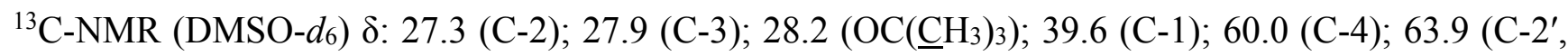
Ar), 64.2 (C-3', Ar), $77.2\left(\mathrm{OC}\left(\mathrm{CH}_{3}\right) 3\right) ; 116.0$ (C-7', $\left.\mathrm{Ar}\right) ; 117.1$ (C-8', $\left.\mathrm{Ar}\right) ; 121.2$ (C-5', Ar); 129.8 (C-6', Ar); $143.4\left(C-4 a^{\prime}, C-8 a^{\prime}\right.$, Ar); $145.4\left(C-4 a^{\prime}, C-8 a^{\prime}, A r\right) ; 155.5(C=O) ; 159.6(C=N)$.

\subsubsection{Standard Procedure for Reduction of Aldimines 4a-f into $N$-Boc Monoprotected Diamines 5a-f}

In a $50 \mathrm{~mL}$ two-necked round-bottomed flask, provided with a magnetic stirrer and reflux condenser, compound $4(5 \mathrm{mmol})$ was dissolved in methanol p.a. $(30 \mathrm{~mL})$ under vigorous stirring and cooled at $0{ }^{\circ} \mathrm{C}$. To this solution was added by small portions commercial sodium borohydride $\mathrm{NaBH}_{4}(0.95 \mathrm{~g}$, $25 \mathrm{mmol}$ ) over a period of $20 \mathrm{~min}$. The resulting suspension was stirred at $50{ }^{\circ} \mathrm{C}$ for $24 \mathrm{~h}$ (monitored by TLC on 0.2-mm precoated plates of silica gel 60 F-254, Merck). After cooling down to room temperature, the volatile compounds were removed in a rotary evaporator under reduced pressure, then deionized water $(40 \mathrm{~mL})$ was added in one portion to the crude residue. The mixture was transferred to a separating funnel and was extracted with dichloromethane $(3 \times 50 \mathrm{~mL})$. The combined organic phases were dried over magnesium sulphate $\mathrm{MgSO}_{4}$, filtered on filter paper and the solvent was eliminated in vacuo. The crude residue was dried under high vacuum $\left(10^{-2}\right.$ Torr $)$ at $25{ }^{\circ} \mathrm{C}$ for $2 \mathrm{~h}$. The desired compound 5 was obtained as yellowish viscous oil and was further used without purification.

(4-Phenylmethylamino-butyl)-carbamic acid tert-butyl ester (5a). Compound 5a was prepared in 93\% yield (1.25 g) from [4-(benzylidene-amino)-butyl]-carbamic acid tert-butyl ester 4a (1.38 g, $5 \mathrm{mmol})$ according to the standard procedure that gave 5a as yellowish viscous oil. ${ }^{1} \mathrm{H}-\mathrm{NMR}$ (DMSO- $\left.d_{6}\right) \delta$ : 1.37 (s, 9H, $\mathrm{Me}_{3} \mathrm{C}$ ); 1.34-1.42 (m, 4H, CH $2, \mathrm{H}-2, \mathrm{H}-3$ ); 2.45 (t, 2H, J=6.2 Hz, $\mathrm{CH}_{2} \mathrm{NH}, \mathrm{H}-4$ ); 2.89-2.91 (m, $2 \mathrm{H}, \mathrm{CH}_{2} \mathrm{NH}, \mathrm{H}-1$ ); 3.66 (s, 2H, $\mathrm{ArC}_{2} \mathrm{NH}$ ); 6.78-6.82 (br s, 1H, NHCO); 7.18-7.13 (m, 1H, H-4', Ar); 7.26-7.33 (m, 4H, H-2', H-3', H-5', H-6', Ar). ${ }^{13} \mathrm{C}-\mathrm{NMR}$ (DMSO-d6) $\delta: 27.4$ (C-3); 26.8 (C-2); 39.8 (C-1); $48.4(\mathrm{C}-4) ; 53.0\left(\operatorname{Ar}_{\underline{C}} \mathrm{H}_{2} \mathrm{NH}\right) ; 77.2\left(\mathrm{O}^{\mathrm{C}}\left(\mathrm{CH}_{3}\right)_{3}\right) ; 126.3\left(\mathrm{C}-4^{\prime}, \mathrm{Ar}\right) ; 127.8\left(\mathrm{C}-2^{\prime}, \mathrm{C}-6{ }^{\prime}, \mathrm{Ar}\right) ; 128.0$ (C-3', C-5', Ar); 141,0 (C-1', Ar); 155,5 (C=O).

[4-(4-Methoxy-phenylmethylamino)-butyl]-carbamic acid tert-butyl ester (5b). Compound $\mathbf{5 b}$ was prepared in $99 \%$ yield $(1.52 \mathrm{~g})$ from $\{4$-[(4-methoxy-benzylidene)-amino]-butyl $\}$-carbamic acid 
tert-butyl ester $\mathbf{4 b}(1.53 \mathrm{~g}, 5 \mathrm{mmol})$ according to the standard procedure that gave $\mathbf{5 b}$ as yellowish viscous oil. ${ }^{1} \mathrm{H}-\mathrm{NMR}$ (DMSO-d6) $\delta: 1.37$ (s, 9H, Me 3 C); 1.33-1.41 (m, 4H, H-2, H-3); 2.45 (t, 2H, $\left.J=6.5 \mathrm{~Hz}, \underline{\mathrm{C}}_{2} \mathrm{NH}, \mathrm{H}-4\right) ; 2.88-2.90$ (m, 2H, $\left.\underline{\mathrm{H}}_{2} \mathrm{NHCO}, \mathrm{H}-1\right) ; 3.60$ (s, 2H, $\mathrm{ArC}_{2} \underline{\mathrm{H}}_{2} \mathrm{NH}$ ); 3.72 (s, 3H,

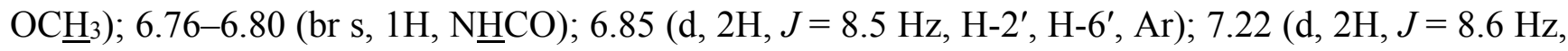
$\left.\mathrm{H}-3{ }^{\prime}, \mathrm{H}-5{ }^{\prime}, \mathrm{Ar}\right) .{ }^{13} \mathrm{C}-\mathrm{NMR}$ (DMSO-d6) $\delta: 26.6$ (C-2); 27.4 (C-3); $28.2\left(\mathrm{OC}\left(\underline{\mathrm{C}} \mathrm{H}_{3}\right) 3\right) ; 39.8(\mathrm{C}-4) ; 48.2$

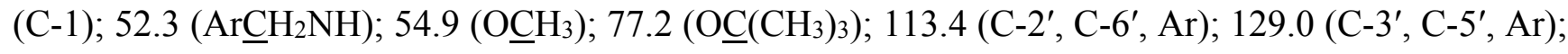
132.6 (C-1', Ar); $155.5(\mathrm{C}=\mathrm{O}) ; 158.0\left(\mathrm{C}-4^{\prime}, \mathrm{Ar}\right)$.

[4-(2-Chloro-phenylmethylamino)-butyl]-carbamic acid tert-butyl ester (5c). Compound 5c was prepared in $85 \%$ yield $(1.33 \mathrm{~g})$ from $\{4$-[(2-chloro-benzylidene)-amino]-butyl $\}$-carbamic acid tert-butyl ester $4 \mathbf{c}(1.55 \mathrm{~g}, 5 \mathrm{mmol})$ according to the standard procedure that gave $\mathbf{5 c}$ as yellowish viscous oil. ${ }^{1} \mathrm{H}-\mathrm{NMR}$ (DMSO-d6) $\delta: 1.37$ (s, 9H, Me $3 \mathrm{C}$ ); 1.34-1.43 (m, 4H, $\left.\underline{\mathrm{CH}}_{2}, \mathrm{H}-2, \mathrm{H}-3,4 \mathrm{H}\right) ; 2.47-2.52$ (m, 2H, $\left.\mathrm{ArCH}_{2} \mathrm{NH}, \mathrm{H}-4\right) ; 2.88-2.92$ (m, 2H, $\left.\underline{\mathrm{H}}_{2} \mathrm{NHCO}, \mathrm{H}-1\right) ; 3.75$ (s, 2H, $\mathrm{ArC}_{2} \mathrm{NH}$ ); 6.77-6.80 (br s, 1H, NECO); 7.21-7.33 (m, 2H, H-4', H-5', Ar); 7.37-7.4 (m, 1H, H-6', Ar); 7.5-7.53 (m, 1H, H-3', Ar).

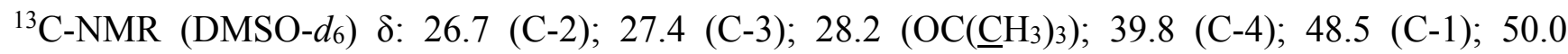
$\left(\mathrm{Ar}_{\underline{C}}{ }_{2} \mathrm{NH}\right) ; 77.2\left(\mathrm{O} \underline{\mathrm{C}}\left(\mathrm{CH}_{3}\right)_{3}\right) ; 126.9$ (C-5', Ar); 128.0 (C-4', Ar); 128.9 (C-6', Ar); 129.6 (C-3', Ar); 132.5 (C-1', Ar); 138.2 (C-2', Ar); $155.5(\mathrm{C}=\mathrm{O})$.

[4-(3-Methoxy-phenylmethylamino)-butyl]-carbamic acid tert-butyl ester (5d). Compound 5d was prepared in $90 \%$ yield (1.39 g) from $\{4$-[(3-methoxy-benzylidene)-amino]-butyl $\}$-carbamic acid tert-butyl ester $4 \mathbf{d}(1.53 \mathrm{~g}, 5 \mathrm{mmol})$ according to the standard procedure that gave $\mathbf{5 d}$ as pale pink viscous oil. ${ }^{1} \mathrm{H}-\mathrm{NMR}$ (DMSO-d6) $\delta: 1.37$ (s, 9H, Me ${ }_{3} \mathrm{C}$ ); 1.34-1.46 (m, 4H, H-2, H-3); 2.45 (t, 2H, $\left.J=6.4 \mathrm{~Hz}, \mathrm{CH}_{2} \mathrm{NH}, \mathrm{H}-4\right)$; 2.89-2.91 (m, 2H, $\left.\underline{\mathrm{H}}_{2} \mathrm{NHCO}, \mathrm{H}-1\right) ; 3.64$ (s, 2H, $\mathrm{ArC}_{2} \underline{\mathrm{H}}_{2} \mathrm{NH}$ ); 3.74 (s, 3H, $\mathrm{OCH}_{3}$ ); 6.75-6.80 (br s, 1H, NHCO); 6.75-6.91 (m, 3H, H-4', H-5', H-6', Ar); 7.17-7.22 (m, 1H,

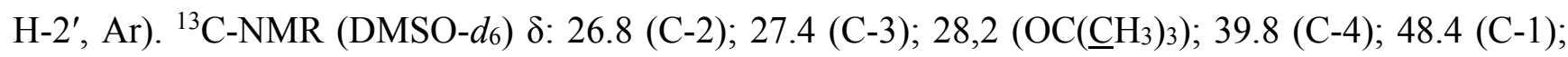
$52.9\left(\mathrm{ArCH}_{2} \mathrm{NH}\right) ; 54.8\left(\mathrm{OCH}_{3}\right) ; 77.2\left(\mathrm{OC}\left(\mathrm{CH}_{3}\right) 3\right) ; 111.8$ (C-5', $\left.\mathrm{Ar}\right) ; 113.2$ (C-6', Ar); $120.0\left(\mathrm{C}-4^{\prime}, \mathrm{Ar}\right)$; 128.9 (C-2', Ar); 142.8 (C-1', Ar); $155.5(\mathrm{C}=\mathrm{O}) ; 159.2$ (C-3', Ar).

\{4-[(Benzo[1,3]dioxol-5-ylmethyl)-amino]-butyl\}-carbamic acid tert-butyl ester (5e). Compound 5e was prepared in 97\% yield (1.56 g) from $\{4$-[(benzo[1,3]dioxol-5-ylmethylene)-amino]-butyl $\}$-carbamic acid tert-butyl ester $4 \mathrm{e}(1.60 \mathrm{~g}, 5 \mathrm{mmol})$ according to the standard procedure that gave $\mathbf{5 e}$ as yellowish viscous oil. ${ }^{1} \mathrm{H}-\mathrm{NMR}$ (DMSO-d6) $\delta: 1.37$ (s, 9H, Me 3 C); 1.23-1.40 (m, 4H, H-2, H-3); 2.43 (t, 2H,

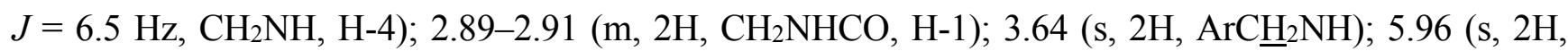
H-2', Ar); 6.73-6.82 (br s, 1H, NHCO); 6.73-6.90 (m, 3H, H-4', H-6', H-7', Ar). ${ }^{13} \mathrm{C}-\mathrm{NMR}$ (DMSO-d6)

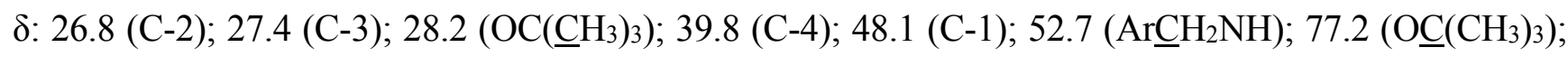
100.6 (C-2', Ar); 107.7 (C-6', Ar); 108.2 (C-7', Ar); 120.8 (C-4', Ar); 135.0 (C-5', Ar); 145.7 (C-3a', C-7a', Ar); 147.1 (C-3a', C-7a', Ar); $155.5(\mathrm{C}=\mathrm{O})$.

\{4-[(2,3-Dihydro-benzo[1,4]dioxin-6-ylmethyl)-amino]-butyl\}-carbamic acid tert-butyl ester (5f). Compound $\mathbf{5 f}$ was prepared in $88 \%$ yield (1.48 g) from \{4-[(2,3-dihydro-benzo[1,4]dioxin-6-ylmethylene)amino]-butyl $\}$-carbamic acid tert-butylester $\mathbf{4 f}(1.67 \mathrm{~g}, 5 \mathrm{mmol})$ according to the standard procedure that gave $\mathbf{5 f}$ as yellowish viscous oil. ${ }^{1} \mathrm{H}-\mathrm{NMR}$ (DMSO-d6) $\delta: 1.37\left(\mathrm{~s}, 9 \mathrm{H}, \mathrm{Me}_{3} \mathrm{C}\right) ; 1.33-1.43(\mathrm{~m}, 4 \mathrm{H}$, $\mathrm{H}-2, \mathrm{H}-3) ; 2.42$ (t, 2H, $\left.J=6.4 \mathrm{~Hz}, \mathrm{CH}_{2} \mathrm{NH}, \mathrm{H}-4\right) ; 2.88-2.90$ (m, 2H, $\left.\mathrm{CH}_{2} \mathrm{NHCO}, \mathrm{H}-1\right) ; 3.53$ (s, 2H, 
$\mathrm{ArCH}_{2} \mathrm{NH}$ ); 4.20 (s, 4H, H-2', H-3', Ar); 6.75-6.80 (br s, 1H, NHCO); 6.75-6.80 (m, 3H, H-5', H-7', H-8', Ar). ${ }^{13} \mathrm{C}-\mathrm{NMR}$ (DMSO-d6) $\delta: 26.8$ (C-2); 27.4 (C-3); $28.2\left(\mathrm{OC}\left(\underline{\mathrm{CH}}_{3}\right) 3\right) ; 39.8$ (C-4); 48.2 (C-1); 52.3 $\left(\mathrm{Ar} \underline{\mathrm{C}} \mathrm{H}_{2} \mathrm{NH}\right) ; 63.9$ (C-2', C-3', Ar); 64.0 (C-2', C-3', Ar); $77.2\left(\mathrm{OC}\left(\mathrm{CH}_{3}\right) 3\right) ; 116.4$ (C-7', Ar); 116.5 (C-8', Ar); 120.6 (C-5', Ar); 134.0 (C-6', Ar); 141.9 (C-4a', C-8a', Ar); 143.0 (C-4a', C-8a', Ar); 155.5 (C=O).

3.1.4. Standard Procedure for the Preparation of Hydrochloride Salts $6 \mathbf{a}-\mathbf{f}$ after Deprotection of $N$-Boc Monoprotected Diamines 5a-f

In a $100 \mathrm{~mL}$ two-necked round-bottomed flask provided with a magnetic stirrer and condenser, $N$-Boc monoprotected diamine 5 (12.1 mmol, 1 equiv.) was solubilized in 1,4-dioxane ( $80 \mathrm{~mL})$ at room temperature under vigorous stirring for $10 \mathrm{~min}$. To this homogeneous solution was added dropwise for $1 \mathrm{~h}$ a solution of $6 \mathrm{M} \mathrm{HCl}(20 \mathrm{~mL})$. The reaction mixture was stirred during $4 \mathrm{~h}$ at $25^{\circ} \mathrm{C}$ and was concentrated in a rotary evaporator under reduced pressure for elimination of volatile compounds. To the crystallized crude reaction mixture was added $60 \mathrm{~mL}$ of anhydrous $\mathrm{Et}_{2} \mathrm{O}$ and after triturating, the insoluble salt 6 was collected by filtration, on a Büchner funnel (porosity $\mathrm{N}^{\circ} 4$ ) then washed with $6 \times 10 \mathrm{~mL}$ of $\mathrm{Et}_{2} \mathrm{O}$. The desired salt 6 was dried under high vacuum $\left(10^{-2} \mathrm{Torr}\right)$ at $25^{\circ} \mathrm{C}$ for $1 \mathrm{~h}$ that gave a yellowish or white powder and was further used without purification.

N-1-Phenylmethyl-butane-1,4-diamine hydrochloride (6a). Compound 6a was prepared in 84\% yield (2.18 g) from (4-phenylmethylamino-butyl)-carbamic acid tert-butyl ester 5a (3.37 g, $12.1 \mathrm{mmol})$ according to the standard procedure as yellowish powder. $\mathrm{Mp}>260{ }^{\circ} \mathrm{C} .{ }^{1} \mathrm{H}-\mathrm{NMR}$ (DMSO- $d_{6}$ ) $\delta$ : 1.57-1.67 (m, 2H, CH $2, \mathrm{H}-3)$; 1.70-1.81 (m, 2H, CH $2, \mathrm{H}-2) ; 2.79$ (t, 2H, $\left.J=7.3 \mathrm{~Hz}, \mathrm{CH}_{2} \mathrm{NH}, \mathrm{H}-4\right)$; 2.89 (t, 2H, $J=7.5 \mathrm{~Hz}, \mathrm{CH}_{2} \mathrm{NH}_{2}, \mathrm{H}-1$ ); 4.10 (s, 2H, $\left.\mathrm{CH}_{2} \mathrm{NH}, \mathrm{H}-4\right)$; 7.4-7.45 (m, 3H, H-3', H-4', H-5', Ar); 7.58-7.62 (m, 2H, H-2', H-6', Ar); 8.19 (br s, 2H, NH 2 ); 9.57 (br s, 1H, NH). ${ }^{13} \mathrm{C}-\mathrm{NMR}$ (DMSO-d6)

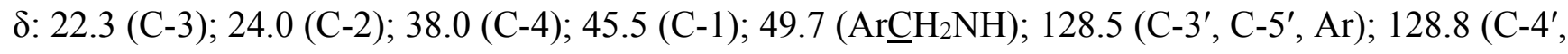
Ar); 130.1 (C-2', C-6', Ar); 132.0 (C-1', Ar).

N-1-(4-Methoxy-phenylmethyl)-butane1,4-diamine hydrochloride (6b). Compound $\mathbf{6 b}$ was prepared in 97\% yield (2.87 g) from (4-methoxyphenylmethylamino-butyl)-carbamic acid tert-butyl ester $\mathbf{5 b}$ (3.73 g, $12.1 \mathrm{mmol}$ ) according to the standard procedure as pale brownish powder. $\mathrm{Mp}>260{ }^{\circ} \mathrm{C} .{ }^{1} \mathrm{H}-\mathrm{NMR}$ (DMSO-d6) $\delta:$ 1.57-1.66 (m, 2H, H-3); 1.69-1.79 (m, 2H, H-2); 2.77-2.84 (m, 4H, H-1, H-4); 3.76 (s, $\left.3 \mathrm{H}, \mathrm{OC}_{3}\right) ; 4.03$ (s, 2H, $\left.\operatorname{ArC}_{2} \mathrm{NH}\right) ; 6.97$ (d, 2H, J=8.7 Hz, H-2', H-6', Ar); 7.51 (d, 2H, J=8.7 Hz,

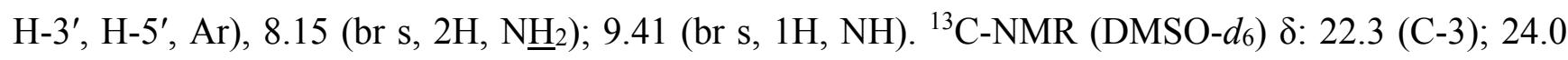
(C-2); 38.0 (C-4); 45.3 (C-1); $49.2\left(\mathrm{ArCH}_{2} \mathrm{NH}\right) ; 55.2\left(\mathrm{OCH}_{3}\right) ; 113.9$ (C-2', C-6', Ar); 123.7 (C-1', Ar); 131.6 (C-3', C-5', Ar); 159.6 (C-4', Ar).

N-1-(2-Chloro-phenylmethyl)-butane1,4-diamine hydrochloride (6c). Compound $\mathbf{6 c}$ was prepared in 98\% yield (2.95 g) from (2-chlorophenylmethylamino-butyl)-carbamic acid tert-butyl ester 5c (3.79 g, $12.1 \mathrm{mmol})$ according to the standard procedure as pale brownish powder. $\mathrm{Mp}=206-208{ }^{\circ} \mathrm{C}$. ${ }^{1} \mathrm{H}-\mathrm{NMR}$ (DMSO- $\left.d_{6}\right) \delta:$ 1.60-1.69 (m, 2H, H-3); 1.74-1.84 (m, 2H, H-2); 2.73-2.84 (m, 2H, $\mathrm{CH}_{2} \mathrm{NH}$, $\mathrm{H}-4)$; 2.93-3.02 (m, 2H, $\left.\mathrm{CH}_{2} \mathrm{NH}_{2}, \mathrm{H}-1\right)$; 4.23 (t, 2H, $J=5.9 \mathrm{~Hz}, \mathrm{ArC}_{2} \mathrm{NH}$ ); 7.39-7.48 (m, 2H, H-4', H-5', Ar); 7.52-7.56 (m, 1H, H-6', Ar); 7.81-7.85 (m, 1H, H-3', Ar); 8.18 (br s, 2H, NH $2,2 \mathrm{H}$ ); 9.68 


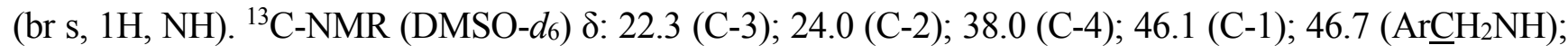
127.5 (C-5', Ar); 129.5 (C-4', Ar); 129.9 (C-1', Ar); 130.7 (C-6', Ar); 131.9 (C-3', Ar); 133.5 (C-2', Ar).

N-1-(3-Methoxy-phenylmethyl)-butane-1,4-diamine hydrochloride (6d). Compound $\mathbf{6 d}$ was prepared in 98\% yield (2.98 g) from [4-(3-methoxy-phenylmethylamino)-butyl]-carbamic acid tert-butyl ester 5d ( $3.73 \mathrm{~g}, 12.1 \mathrm{mmol}$ ) according to the standard procedure as pale brownish powder. $\mathrm{Mp}=190-192{ }^{\circ} \mathrm{C}$. ${ }^{1} \mathrm{H}-\mathrm{NMR}$ (DMSO-d6) $\delta$ : 1.58-1.67 (m, 2H, H-3); 1.71-1.81 (m, 2H, H-2); 2.78 (t, 2H, $J=7.3 \mathrm{~Hz}$, $\left.\mathrm{CH}_{2} \mathrm{NH}, \mathrm{H}-4\right) ; 2.87$ (t, 2H, $J=7.6 \mathrm{~Hz}, \mathrm{CH}_{2} \mathrm{NH}_{2}, \mathrm{H}-1$ ); 3.77 (s, 3H, OCH 3$) ; 4.08$ (t, 2H, $J=5.6 \mathrm{~Hz}$, $\mathrm{ArCH}_{2} \mathrm{NH}$ ); 6.94-6.97 (m, 1H, H-5', Ar); 7.12-7.14 (m, 1H, H-6', Ar); 7.29-7.35 (m, 2H, H-2', H-4', $\mathrm{Ar}$ ); 8.18 (br s, 2H, NH ); 9.58 (br s, $1 \mathrm{H}, \mathrm{NH}$ ). ${ }^{13} \mathrm{C}-\mathrm{NMR}$ (DMSO-d6) $\delta: 22.3$ (C-3); 24.0 (C-2); 38.0 (C-4); 45.5 (C-1); $49.7\left(\mathrm{Ar}_{\underline{C}} \mathrm{H}_{2} \mathrm{NH}\right) ; 55.2\left(\mathrm{OCH}_{3}\right) ; 114.5$ (C-5', Ar); 115.5 (C-6', Ar); 122.0 (C-4', Ar); 129.6 (C-2', Ar); 133.4 (C-1', Ar); 159.2 (C-3', Ar).

N-1-Benzo[1,3]dioxol-5-ylmethyl-butane-1,4-diamine hydrochloride (6e). Compound 6e was prepared in $72 \%$ yield $(2.25 \mathrm{~g})$ from $\{4$-[(benzo[1,3]dioxol-5-ylmethyl)-amino]-butyl $\}$-carbamic acid tert-butyl ester $5 \mathrm{e}$ (3.90 g, $12.1 \mathrm{mmol})$ according to the standard procedure as pale brownish powder. $\mathrm{Mp}>260{ }^{\circ} \mathrm{C}$. ${ }^{1} \mathrm{H}-\mathrm{NMR}$ (DMSO-d6) $\delta$ : 1.58-1.67 (m, 2H, H-3); 1.71-1.81 (m, 2H, H-2); 2.78 (t, 2H, $J=7.3 \mathrm{~Hz}$, $\left.\mathrm{CH}_{2} \mathrm{NH}, \mathrm{H}-4\right) ; 2.87$ (t, 2H, $J=7.6 \mathrm{~Hz}, \mathrm{CH}_{2} \mathrm{NH}_{2}, \mathrm{H}-1$ ); 3.77 (s, 3H, $\left.\mathrm{OCH}_{3}\right) ; 4.08$ (t, $2 \mathrm{H}, J=5.6 \mathrm{~Hz}$, $\mathrm{ArCH}_{2} \mathrm{NH}$ ); 6.94-6.97 (m, 1H, H-5', Ar); 7.12-7.14 (m, 1H, H-6', Ar); 7.29-7.35 (m, 2H, H-2', H-4', Ar); 8.18 (br s, 2H, NH2); 9.58 (br s, 1H, NH). ${ }^{13} \mathrm{C}-\mathrm{NMR}$ (DMSO-d6) $\delta: 22.3$ (C-3); 24.0 (C-2); 38.0 (C-4); 45.2 (C-1); 49.4 (Ar $\left.\underline{C H}_{2} \mathrm{NH}\right) ; 101.2$ (C-2', Ar); 108.2 (C-6', Ar); 110.4 (C-7', Ar); 124.1 (C-4', Ar); 125.4 (C-5', Ar); 147.2 (C-3a', C-7a', Ar); 147.6 (C-3a', C-7a', Ar).

N-1-(2,3-Dihydro-benzo[1,4]dioxin-6-ylmethyl)-butane-1,4-diamine hydrochloride (6f). Compound 6e was prepared in 92\% yield (3.04 g) from \{4-[(2,3-dihydro-benzo[1,4]dioxin-6-ylmethyl)-amino]butyl \}-carbamic acid tert-butyl ester $\mathbf{5 f}(4.07 \mathrm{~g}, 12.1 \mathrm{mmol})$ according to the standard procedure as pale brownish powder. $\mathrm{Mp}=239-241{ }^{\circ} \mathrm{C} .{ }^{1} \mathrm{H}-\mathrm{NMR}\left(\mathrm{DMSO}-d_{6}\right) \delta$ : $1.57-1.66$ (m, 2H, H-3); $1.68-1.78$

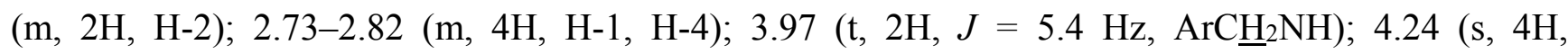
$\mathrm{OCH}_{2} \mathrm{CH}_{2} \mathrm{O}$ ); 6.87 (d, 1H, $\left.J=8.2 \mathrm{~Hz}, \mathrm{H}^{-7}{ }^{\prime}, \mathrm{Ar}\right) ; 7.01-7.04$ (m, 1H, H-8', Ar); 7.15 (m, 1H, H-5', Ar); 8.18 (br s, 2H, NH ); 9.43 (br s, 1H, NH). ${ }^{13} \mathrm{C}-\mathrm{NMR}$ (DMSO-d6) $\delta: 22.3$ (C-3); 24.0 (C-2); 38.0 (C-4); 45.2 (C-1); 49.1 ( $\left.\mathrm{ArCH}_{2} \mathrm{NH}\right) ; 64.0$ (C-2', Ar); 64.1 (C-3', Ar); 117.0 (C-7', Ar); 119.0 (C-8', Ar); 123.2 (C-5', Ar); 124.7 (C-6', Ar); 143.1 (C-4a', C-8a', Ar); 143.8 (C-4a', C-8a', Ar).

\subsubsection{Standard Procedure for the Preparation of $N$-Substituted 5-Arylidene Rhodanine Derivatives} 9a-f under Microwave Irradiation Using “One-Pot Two-steps” Protocol

In a $10 \mathrm{~mL}$ glass tube were placed successively bis-(carboxymethyl)trithiocarbonate $7(0.11 \mathrm{~g}$, $0.50 \mathrm{~mol}, 1$ equiv.), dimethoxyethane $(2 \mathrm{~mL})$, triethylamine $(135 \mathrm{~mL}, 101 \mathrm{mg}, 1 \mathrm{mmol}, 2$ equiv. or $202 \mathrm{~mL}, 152 \mathrm{mg}, 1.5 \mathrm{mmol}, 3$ equiv.) and hydrochloride salt 6 ( $0.5 \mathrm{mmol}, 1$ equiv.). The glass tube was sealed with a snap cap and placed in the Monowave ${ }^{\circledR} 300$ Anton Paar microwave cavity ( $p=800$ Watt). The reaction mixture was irradiated at $90{ }^{\circ} \mathrm{C}$ for $15-60 \mathrm{~min}$. under vigorous magnetic stirring. After microwave dielectric heating, the crude reaction mixture was allowed to cool down at room temperature, aldehyde 3 (0.5 mol, 1 equiv.) was added to the cooled reaction mixture which was immediately 
submitted to microwave irradiation at $110{ }^{\circ} \mathrm{C}$ for $5-30 \mathrm{~min}$. After cooling down to room temperature, the volatile compounds of the reaction mixture were removed in a rotary evaporator under reduced pressure. To the crude reaction mixture was added $4 \mathrm{~mL}$ of $\mathrm{MeOH}$ and after triturating, the insoluble product 9 was collected by filtration on a Büchner funnel (porosity $\mathrm{N}^{\circ} 4$ ), washed with deionized water $(5 \mathrm{~mL})$, triturated and mixing with ethanol $(3 \times 5 \mathrm{~mL})$ during $3 \mathrm{~h}$, washed successively with ethanol $(5 \mathrm{~mL})$ and anhydrous ether $(5 \times 2 \mathrm{~mL})$, then dried under high vacuum $\left(10^{-2}\right.$ Torr $)$ at $25^{\circ} \mathrm{C}$ for $1 \mathrm{~h}$. The desired compound 9 was eventually purified by recrystallization in EtOH after control by ${ }^{1} \mathrm{H}-\mathrm{NMR}$ in solution of $\mathrm{CDCl}_{3} / \mathrm{TFA}(98: 2)$.

(5Z)3-[4-(4-Methoxyphenylmethylamino)butyl]-5-(1,3-benzodioxol-5-ylmethylene)-2-thioxo-1,3thiazolidin-4-one (9a). According to the standard procedure, compound 9a was prepared in 10\% yield (23 mg) from N-1-(4-methoxy-phenylmethyl)-butane-1,4-diamine hydrochloride $6 \mathbf{b}$ (122.3 mg, $0.5 \mathrm{mmol}, 1$ equiv.), triethylamine (202 $\mu \mathrm{L}, 152 \mathrm{mg}, 1.5 \mathrm{mmol}, 3$ equiv.) and piperonaldehyde $3 \mathbf{e}$ (75.1 mg, $0.5 \mathrm{mmol}, 1$ equiv.) after $30 \mathrm{~min}$. at $90{ }^{\circ} \mathrm{C}$, followed by a second reaction time of $30 \mathrm{~min}$. at $110{ }^{\circ} \mathrm{C}$ (for condensation step with 3e), which gave 9a as a yellowish powder. $\mathrm{Mp}=170-229{ }^{\circ} \mathrm{C}$ (decomposition). ${ }^{1} \mathrm{H}-\mathrm{NMR}\left(\mathrm{CDCl}_{3} / \mathrm{TFA} 98: 2\right)$ ) : 1.61-1.69 (m, 4H, CH $2, \mathrm{H}-2$ ", H-3"); 3.05-3.11 (m, $2 \mathrm{H}, \mathrm{ArC}_{2} \mathrm{NH}$ ); 3.73 (s, 3H, OC 3 ); 4.00-4.08 (m, 4H, CH $\left.2, \mathrm{H}-1^{\prime \prime}, \mathrm{H}-4^{\prime \prime}\right), 5.97$ (s, 2H, CH $2, \mathrm{H}-2^{\prime}$ ); 6.80-7.16 (m, 7H, H-2"', H-3"', H-5"', H-6"', H-4', H-6', H-7', Ar); 7.55 (br s, 1H, NH); 7.61 (s, 1H, $\underline{\mathrm{HC}}=\mathrm{C}) .{ }^{13} \mathrm{C}-\mathrm{NMR}\left(\mathrm{CDCl}_{3} / \mathrm{TFA} 98: 2\right) \delta: 23.1\left(\mathrm{C}-2^{\prime \prime}, 3^{\prime \prime}\right) ; 23.8\left(\mathrm{C}-3^{\prime \prime}, 2^{\prime \prime}\right) ; 44.2$ (C-4"', C-1"); 47.0

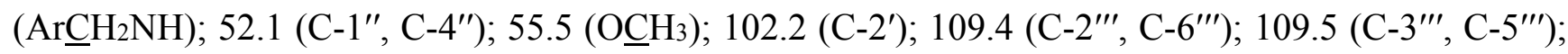
$115.0\left(\mathrm{C}-6^{\prime}\right) ; 120.0\left(\mathrm{C}-1^{\prime \prime \prime}\right) ; 127.5(\underline{\mathrm{C}}=\mathrm{CH}) ; 128.2\left(\mathrm{C}-7^{\prime}\right) ; 131.2\left(\mathrm{C}-4^{\prime}\right) ; 135.0(\mathrm{C}=\underline{\mathrm{CH}}) ; 148.8\left(\mathrm{C}-5^{\prime}\right)$; 148.9 (C-4"'); 150.6 (C-3'a); 150.9 (C-7'a); 169.4 ( $\underline{\mathrm{C}}=\mathrm{O}, \mathrm{C}-4) ; 192.9$ ( $\underline{\mathrm{C}}=\mathrm{S}, \mathrm{C}-2)$. HRMS, $m / z$ : 457.1256 found (calculated for $\mathrm{C}_{23} \mathrm{H}_{25} \mathrm{~N}_{2} \mathrm{O}_{4} \mathrm{~S}_{2}[\mathrm{M}+\mathrm{H}]^{+}$requires 457.1253).

(5Z)3-[4-(4-Methoxyphenylmethylamino)butyl]-5-(4-methoxybenzylidene)-2-thioxo-1,3-thiazolidin-4one $(9 \mathrm{~b})$. According to the standard procedure, compound $9 \mathrm{~b}$ was prepared in $6 \%$ yield (13.3 $\mathrm{mg}$ ) from $\mathrm{N}$-1-(4-methoxy-phenylmethyl)-butane-1,4-diamine hydrochloride $6 \mathbf{b}$ (122.3 mg, $0.5 \mathrm{mmol}, 1$ equiv.), triethylamine $(202 \mu \mathrm{L}, 152 \mathrm{mg}, 1.5 \mathrm{mmol}, 3$ equiv.) and 4-methoxybenzaldehyde $\mathbf{3 b}(68.1 \mathrm{mg}, 0.5 \mathrm{mmol}$, 1 equiv.) after $30 \mathrm{~min}$. at $90{ }^{\circ} \mathrm{C}$, followed by a second reaction time of $30 \mathrm{~min}$. at $110{ }^{\circ} \mathrm{C}$ (for condensation step with 3b), which gave 9b as a yellowish powder. $\mathrm{Mp}=253-255{ }^{\circ} \mathrm{C} .{ }^{1} \mathrm{H}-\mathrm{NMR}$ $\left(\mathrm{CDCl}_{3} / \mathrm{TFA} 98: 2\right) \delta$ : 1.67-1.73 (m, 4H, CH $\left.2, \mathrm{H}-2^{\prime \prime}, \mathrm{H}-3^{\prime \prime}\right) ; 3.07-3.13$ (m, 2H, $\left.\operatorname{ArC}_{2} \mathrm{NH}\right) ; 3.81$ (s, 6H, $\mathrm{ArOC}_{3}$ ); 4.04-4.11 (s, 4H, CH $\left.2, \mathrm{H}-1^{\prime \prime}, \mathrm{H}-4^{\prime \prime}\right), 6.94$ (dd, 4H, J=8.8 Hz, H-2', H-6', H-2'"', H-6"', Ar); 7.40 (d, 4H, $J=8.8 \mathrm{~Hz}, \mathrm{H}-3^{\prime}, \mathrm{H}-5^{\prime}, \mathrm{H}-3^{\prime \prime \prime}, \mathrm{H}-5^{\prime \prime \prime}, \mathrm{Ar}$ ); 7.60 (br s, 1H, NH); 7.67 (s, 1H, Cㅍ=).

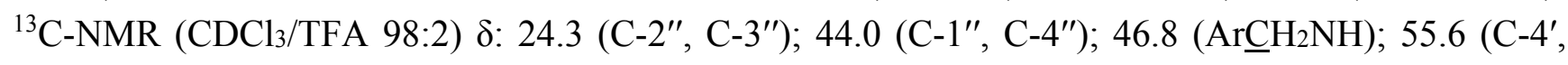
$\left.\mathrm{O}^{-} H_{3}, \mathrm{C}-4^{\prime \prime \prime}, \mathrm{OCH}_{3}\right) ; 115.1$ (C-2', C-6', C-2"', C-6"'); 119.6 (C-1', C-1"'); 126.0 ( $\left.\underline{\mathrm{C}}=\right)$; 133.1 (C-3', C-5', C-3"'", C-5"'); 130.5 (C-5', C-5"'); $134.6(\underline{\mathrm{CH}}=)$; 162.0 (C-4', C-4"'); 169.0 ( $\underline{\mathrm{C}}=\mathrm{O}, \mathrm{C}-4) ; 193.2$ $(\underline{\mathrm{C}}=\mathrm{S}, \mathrm{C}-2)$. HRMS, $m / z$ : 443.1463 found (calculated for $\mathrm{C}_{23} \mathrm{H}_{27} \mathrm{~N}_{2} \mathrm{O}_{3} \mathrm{~S}_{2}[\mathrm{M}+\mathrm{H}]^{+}$requires 443.1460 ).

(5Z)3-[4-(4-Methoxyphenylmethylamino)butyl]-5-(2,3-dihydro-1,4-benzodioxin-6-ylmethylene)-2thioxo-1,3-thiazolidin-4-one (9c). According to the standard procedure, compound 9c was prepared in $5 \%$ yield $(11.8 \mathrm{mg}$ ) from $\mathrm{N}$-1-(4-methoxy-phenylmethyl)-butane-1,4-diamine hydrochloride $\mathbf{6 b}$ (122.3 $\mathrm{mg}$, $0.5 \mathrm{mmol}, 1$ equiv.), triethylamine (202 $\mu \mathrm{L}, 152 \mathrm{mg}, 1.5 \mathrm{mmol}, 3$ equiv.) and 2,3-dihydro-1,4-benzodioxin- 
6-carboxaldehyde $\mathbf{3 f}\left(82.1 \mathrm{mg}, 0.5 \mathrm{mmol}, 1\right.$ equiv.) after $30 \mathrm{~min}$. at $90{ }^{\circ} \mathrm{C}$, followed by a second reaction time of $30 \mathrm{~min}$. at $110{ }^{\circ} \mathrm{C}$ (for condensation step with $\mathbf{3 f}$ ), which gave 9c as a yellowish powder. $\mathrm{Mp}=255-261{ }^{\circ} \mathrm{C} .{ }^{1} \mathrm{H}-\mathrm{NMR}\left(\mathrm{CDCl}_{3} / \mathrm{TFA} 98: 2\right) \delta: 1.68$ (s, 4H, $\left.\underline{\mathrm{H}}_{2}, \mathrm{H}-2^{\prime \prime}, \mathrm{H}-3{ }^{\prime \prime}\right)$; 3.03-3.08 (m, 2H, $\mathrm{ArC}_{2} \mathrm{NH}$ ); 3.73 (s, 3H, OC$\left.\underline{H}_{3}\right) ; 4.07$ (s, 4H, CH $\left.2, \mathrm{H}-1^{\prime \prime}, \mathrm{H}-4^{\prime \prime}\right), 4.20-4.25$ (m, 2H, $\left.\underline{\mathrm{H}}_{2}, \mathrm{H}-2^{\prime}, \mathrm{H}-3^{\prime}\right)$; 6.84-6.97 (m, 7H, H-5', H-7', H-8', H-2"', H-3"', H-5'"', H-6"', Ar); 7.58 (s, 1H, C $\underline{H}=$ ); 7.60 (br s, 1H, $\mathrm{NH}) .{ }^{13} \mathrm{C}-\mathrm{NMR}\left(\mathrm{CDCl}_{3} / \mathrm{TFA} 98: 2\right) \delta: 24.2$ (C-2", C-3"); 44.1 (C-4", C-1"); $47.1\left(\mathrm{ArCH}_{2} \mathrm{NH}\right) ; 55.0$ $\left(\mathrm{O}^{-} \mathrm{H}_{3}\right) ; 64.2\left(\mathrm{C}-2^{\prime}\right) ; 64.8\left(\mathrm{C}-3^{\prime}\right) ; 118.4\left(\mathrm{C}-5^{\prime}, \mathrm{C}-7^{\prime}, \mathrm{C}-8^{\prime}\right) ; 119.7$ (C-2'"', C-6"' $) ; 120.3(\underline{\mathrm{C}}=) ; 125.7$ (C-3"', C-5'"'); 126.8 (C-6'); $135.0(\underline{\mathrm{C}} \mathrm{H}=) ; 143.9$ (C-8'a); 146.7 (C-4'a); $169.5(\underline{\mathrm{C}}=\mathrm{O}, \mathrm{C}-4) ; 193.2(\underline{\mathrm{C}}=\mathrm{S}$, C-2). HRMS, $m / z$ : 471.1412 found (calculated for $\mathrm{C}_{24} \mathrm{H}_{27} \mathrm{~N}_{2} \mathrm{O}_{4} \mathrm{~S}_{2}[\mathrm{M}+\mathrm{H}]^{+}$requires 471.1415 ).

(5Z)3-[4-(4-Methoxyphenylmethylamino)butyl]-5-(4-hydroxy-3-methoxybenzylidene)-2-thioxo-1,3thiazolidin-4-one (9d). According to the standard procedure, compound 9d was prepared in 30\% yield (68.8 mg) from $\mathrm{N}$-1-(4-methoxy-phenylmethyl)-butane-1,4-diamine hydrochloride 6b (122.3 $\mathrm{mg}$, $0.5 \mathrm{mmol}, 1$ equiv.), triethylamine (202 $\mu \mathrm{L}, 152 \mathrm{mg}, 1.5 \mathrm{mmol}, 3$ equiv.) and 4-hydroxy-3methoxybenzaldehyde $3 \mathrm{~g}\left(76.1 \mathrm{mg}, 0.5 \mathrm{mmol}, 1\right.$ equiv.) after $30 \mathrm{~min}$. at $90{ }^{\circ} \mathrm{C}$, followed by a second reaction time of $30 \mathrm{~min}$. at $110{ }^{\circ} \mathrm{C}$ (for condensation step with $\mathbf{3 g}$ ), which gave $9 \mathrm{~d}$ as a yellowish powder. $\mathrm{Mp}=191-193{ }^{\circ} \mathrm{C} .{ }^{1} \mathrm{H}-\mathrm{NMR}\left(\mathrm{CDCl}_{3} / \mathrm{TFA} 98: 2\right) \delta: 1.69$ (m, 4H, $\left.\underline{\mathrm{H}}_{2}, \mathrm{H}-2^{\prime \prime}, \mathrm{H}-3{ }^{\prime \prime}\right) ; 3.06-3.07$ (m, $\left.2 \mathrm{H}, \mathrm{ArCH}_{2} \mathrm{NH}\right) ; 3.72$ (s, 3H, C-4"', $\left.\mathrm{OC}_{3}\right) ; 3.86$ (s, 3H, C-3', $\left.\mathrm{OCH}_{3}\right) ; 4.04-4.08$ (m, 4H, $\mathrm{CH}_{2}$, H-1", H-4"'), 6.81-7.17 (m, 7H, H-2', H-5', H-6', H-2'", H-3"', H-5"', H-6"', Ar); 7.55 (br s, 1H, NH); 7.60 (s, 1H, $\mathrm{C} \underline{\mathrm{H}}=\mathrm{C}) .{ }^{13} \mathrm{C}-\mathrm{NMR}\left(\mathrm{CDCl}_{3} / \mathrm{TFA} 98: 2\right) \delta: 23.1$ (C-2", C-3"); 23.9 (C-2", C-3"); 43.1 (C-1", $\left.\mathrm{C}-4^{\prime \prime}\right) ; 47.0\left(\mathrm{ArCH}_{2} \mathrm{NH}\right) ; 55.5\left(\mathrm{ArOCH}_{3}\right) ; 56.1\left(\mathrm{ArOCH}_{3}\right) ; 112.6\left(\mathrm{C}-6^{\prime}\right) ; 115.0\left(\mathrm{C}-2^{\prime \prime \prime}, \mathrm{C}-6^{\prime \prime \prime}\right) ; 115.6$ $\left(\mathrm{C}-2^{\prime}\right) ; 118.9\left(\mathrm{C}-1^{\prime \prime \prime}\right) ; 121.2(\underline{\mathrm{C}}=)$; $125.9\left(\mathrm{C}-1^{\prime}\right) ; 126.8$ (C-5'); 131.2 (C-3"', C-5"'); 135.9 ( $\left.\underline{\mathrm{C}}=\right)$; 147.2 (C-4"'); 148.9 (C-3'); 160.8 (C-4'); 169.4 ( $\underline{\mathrm{C}}=\mathrm{O}, \mathrm{C}-4)$; 193.1 ( $\underline{\mathrm{C}}=\mathrm{S}, \mathrm{C}-2)$. HRMS, $m / z$ : 459.1412 found (calculated for $\mathrm{C}_{23} \mathrm{H}_{27} \mathrm{~N}_{2} \mathrm{O}_{4} \mathrm{~S}_{2}[\mathrm{M}+\mathrm{H}]^{+}$requires 459.1416 ).

(5Z)3-[4-(3-Methoxyphenylmethylamino)butyl]-5-(1,3-benzodioxol-5-ylmethylene)-2-thioxo-1,3thiazolidin-4-one (9e). According to the standard procedure, compound $9 \mathrm{e}$ was prepared in $21 \%$ yield (48.0 mg) from N-1-(3-methoxy-phenylmethyl)-butane-1,4-diamine hydrochloride 6d (122.3 mg, $0.5 \mathrm{mmol}, 1$ equiv.), triethylamine ( $202 \mu \mathrm{L}, 152 \mathrm{mg}, 1.5 \mathrm{mmol}, 3$ equiv.) and piperonaldehyde $3 \mathbf{e}(75.1 \mathrm{mg}$, $0.5 \mathrm{mmol}, 1$ equiv.) after $15 \mathrm{~min}$. at $90{ }^{\circ} \mathrm{C}$, followed by a second reaction time of $15 \mathrm{~min}$. at $110{ }^{\circ} \mathrm{C}$ (for condensation step with $3 \mathbf{e}$ ), which gave $9 \mathbf{e}$ as a yellowish powder. $\mathrm{Mp}=178-246{ }^{\circ} \mathrm{C}$ (decomposition). ${ }^{1} \mathrm{H}-\mathrm{NMR}\left(\mathrm{CDCl}_{3} / \mathrm{TFA} 98: 2\right)$ ): 1.82 (s, 4H, $\underline{\mathrm{H}}_{2}, \mathrm{H}-2^{\prime \prime}, \mathrm{H}-3$ ") $)$ 3.19-3.22 (m, 2H, $\mathrm{ArC}_{2} \mathrm{NH}$ ); 3.83 (s, $3 \mathrm{H}, \mathrm{OC}_{3}$ ); 4.13-4.23 (m, 4H, CH $\left.2, \mathrm{H}-1^{\prime \prime}, \mathrm{H}-4^{\prime \prime}\right), 6.10$ (s, 2H, $\underline{\mathrm{H}}_{2}, \mathrm{H}-2^{\prime}$ ); 6.92-7.28 (m, 6H, H-2"', H-4"', H-6"', H-4', H-6', H-7', Ar), 7.33-7.38 (m, 1H, H-5"', Ar), 7.55 (br s, 1H, NH); 7.70 (s, 1H, $\mathrm{C} \underline{H}=) .{ }^{13} \mathrm{C}-\mathrm{NMR}\left(\mathrm{CDCl}_{3} / \mathrm{TFA} 98: 2\right) \delta: 23.1$ (C-2", C-3"); 23.9 (C-3", C-2"); 42.9 (C-4", C-1"); 46.8

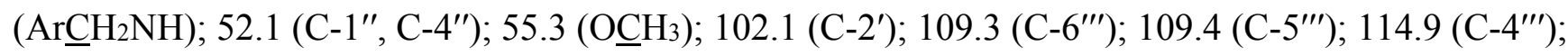
$115.9\left(\mathrm{C}-2^{\prime \prime \prime}\right) ; 119.8\left(\mathrm{C}-1^{\prime \prime \prime}\right) ; 121.8\left(\mathrm{C}-6^{\prime}\right) ; 127.4(\underline{\mathrm{C}}=) ; 127.6\left(\mathrm{C}-5^{\prime}\right) ; 127.9\left(\mathrm{C}-7^{\prime}\right) ; 130.7\left(\mathrm{C}-4^{\prime}\right) ; 134.5$ $(\underline{\mathrm{CH}}=)$; 148.8 (C-7'a); 150.5 (C-3'a); 160.3 (C-3'”); 168.5 ( $\underline{\mathrm{C}}=\mathrm{O}, \mathrm{C}-4) ; 193.1$ ( $\underline{\mathrm{C}}=\mathrm{S}, \mathrm{C}-2)$. HRMS, $m / z$ : 457.1259 found (calculated for $\mathrm{C}_{23} \mathrm{H}_{25} \mathrm{~N}_{2} \mathrm{O}_{4} \mathrm{~S}_{2}[\mathrm{M}+\mathrm{H}]^{+}$requires 457.1257).

(5Z)3-[4-(3-Methoxyphenylmethylamino)butyl]-5-(2,3-dihydro-1,4-benzodioxin-6-ylmethylene)-2thioxo-1,3-thiazolidin-4-one (9f). According to the standard procedure, compound 9c was prepared in 9\% 
yield (21.2 mg) from $\mathrm{N}$-1-(3-methoxy-phenylmethyl)-butane-1,4-diamine hydrochloride 6d (122.3 $\mathrm{mg}$, $0.5 \mathrm{mmol}, 1$ equiv.), triethylamine (202 $\mu \mathrm{L}, 152 \mathrm{mg}, 1.5 \mathrm{mmol}, 3$ equiv.) and 2,3-dihydro-1,4benzodioxin-6-carboxaldehyde $\mathbf{3 f}\left(82.1 \mathrm{mg}, 0.5 \mathrm{mmol}, 1\right.$ equiv.) after $15 \mathrm{~min}$. at $90{ }^{\circ} \mathrm{C}$, followed by a second reaction time of $15 \mathrm{~min}$. at $110{ }^{\circ} \mathrm{C}$ (for condensation step with $\mathbf{3 f}$ ), which gave $9 \mathrm{f}$ as a yellowish powder. $\mathrm{Mp}=247-251{ }^{\circ} \mathrm{C} .{ }^{1} \mathrm{H}-\mathrm{NMR}\left(\mathrm{CDCl}_{3} / \mathrm{TFA} 98: 2\right) \delta: 1.84\left(\mathrm{~s}, 4 \mathrm{H}, \mathrm{CH}_{2}, \mathrm{H}-2^{\prime \prime}, \mathrm{H}-3^{\prime \prime}\right)$;

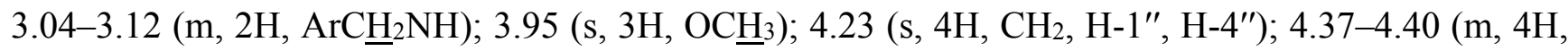
H-2', H-3'); 6.99-7.28 (m, 6H, H-2'"', H-4"', H-5"', H-6"', H-5', H-7', H-8', Ar); 7.60 (br s, 1H, NH); $7.74(\mathrm{~s}, 1 \mathrm{H}, \mathrm{C} \underline{\mathrm{H}}=) .{ }^{13} \mathrm{C}-\mathrm{NMR}\left(\mathrm{CDCl}_{3} / \mathrm{TFA} 98: 2\right) \delta: 24.1\left(\mathrm{C}-2^{\prime \prime}, \mathrm{C}-3^{\prime \prime}\right) ; 44.1$ (C-1", C-4"); 47.3 $\left(\mathrm{ArCH}_{2} \mathrm{NH}\right) ; 64.2\left(\mathrm{C}-2^{\prime}\right) ; 64.8$ (C-3'); 118.5 (C-5', C-7', C-8'); 119.8 (C-4"', C-6"' ); 125.9 (C-2'"', C-5"'); $126.8(\underline{\mathrm{C}}=) ; 135.3(\underline{\mathrm{CH}}=) ; 143.8\left(\mathrm{C}-8^{\prime} \mathrm{a}\right) ; 146.6\left(\mathrm{C}-4{ }^{\prime} \mathrm{a}\right) ; 168.5(\underline{\mathrm{C}}=\mathrm{O}, \mathrm{C}-4) ; 193.3$ ( $\left.\underline{\mathrm{C}}=\mathrm{S}, \mathrm{C}-2\right)$. HRMS, $m / z$ : 471.1412 found (calculated for $\mathrm{C}_{24} \mathrm{H}_{27} \mathrm{~N}_{2} \mathrm{O}_{4} \mathrm{~S}_{2}[\mathrm{M}+\mathrm{H}]^{+}$requires 471.1415 ).

(5Z)3-[4-(3-Methoxyphenylmethylamino)butyl]-5-(3-methoxybenzylidene)-2-thioxo-1,3-thiazolidin-4one $(9 \mathrm{~g})$. According to the standard procedure, compound $9 \mathrm{~g}$ was prepared in 5\% yield (11.1 $\mathrm{mg})$ from $\mathrm{N}$-1-(3-methoxy-phenylmethyl)-butane-1,4-diamine hydrochloride 6d (122.3 mg, $0.5 \mathrm{mmol}, 1$ equiv.), triethylamine ( $202 \mu \mathrm{L}, 152 \mathrm{mg}, 1.5 \mathrm{mmol}, 3$ equiv.) and 3-methoxybenzaldehyde 3d (68.1 mg, $0.5 \mathrm{mmol}$, 1 equiv.) after $30 \mathrm{~min}$. at $90{ }^{\circ} \mathrm{C}$, followed by a second reaction time of $30 \mathrm{~min}$ at $110{ }^{\circ} \mathrm{C}$ (for condensation step with 3d), which gave $9 \mathrm{~g}$ as a yellowish powder. $\mathrm{Mp}=225-227{ }^{\circ} \mathrm{C} .{ }^{1} \mathrm{H}-\mathrm{NMR}\left(\mathrm{CDCl}_{3} / \mathrm{TFA} 98: 2\right)$

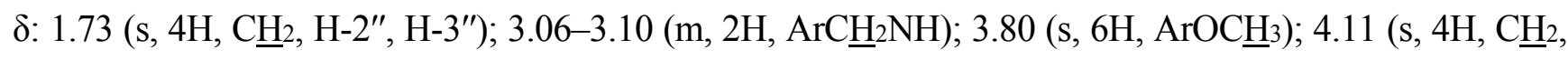
H-1", H-4"'), 6.93-6.96 (m, 4H, H-2', H-6', H-2'"', H-6"', Ar); 7.04 (d, 2H, J = 7.7 Hz, H-4', H-4"'", Ar), 7.32 (m, 2H, H-5', H-5"', Ar), 7.55 (br s, 1H, NH); 7.66 (s, 1H, $\underline{\mathrm{H}}=$ ). ${ }^{13} \mathrm{C}-\mathrm{NMR}\left(\mathrm{CDCl}_{3} / \mathrm{TFA} 98: 2\right) \delta$ : 24.3 (C-2", C-3"); 44.0 (C-1", C-4"); $47.1\left(\mathrm{Ar}^{\prime} \mathrm{H}_{2} \mathrm{NH}\right) ; 55.5\left(\mathrm{ArOC}_{3}\right) ; 115.3$ (C-6', C-6"' $) ; 117.3$ $\left(\mathrm{C}-2^{\prime}, \mathrm{C}-2^{\prime \prime \prime}\right) ; 123.1(\underline{\mathrm{C}}=) ; 123.6\left(\mathrm{C}-4^{\prime}, \mathrm{C}-4^{\prime \prime \prime}\right) ; 130.5\left(\mathrm{C}-5^{\prime}, \mathrm{C}-5^{\prime \prime \prime}\right) ; 134.0(\underline{\mathrm{CH}}=) ; 134.5$ (C-1', C-1"')$)$ 160.0 (C-3', C-3"'); 168.5 ( $\underline{\mathrm{C}}=\mathrm{O}, \mathrm{C}-4) ; 193.3$ ( $\underline{\mathrm{C}}=\mathrm{S}, \mathrm{C}-2)$. HRMS, $m / z: 443.1463$ found (calculated for $\mathrm{C}_{23} \mathrm{H}_{27} \mathrm{~N}_{2} \mathrm{O}_{3} \mathrm{~S}_{2}[\mathrm{M}+\mathrm{H}]^{+}$requires 443.1465$)$.

(5Z)3-[4-(1,3-Benzodioxol-5-ylmethylamino)butyl]-5-(1,3-benzodioxol-5-ylmethylene)-2-thioxo-1,3thiazolidin-4-one (9h). According to the standard procedure, compound $9 \mathbf{h}$ was prepared in 59\% yield (139 mg) from $N$-1-benzo[1,3]dioxol-5-ylmethyl-butane-1,4-diamine hydrochloride 6e (129.4 mg, $0.5 \mathrm{mmol}, 1$ equiv.), triethylamine (135 $\mu \mathrm{L}, 101 \mathrm{mg} ., 1 \mathrm{mmol}, 2$ equiv.) and piperonaldehyde $3 \mathrm{e}(75.1 \mathrm{mg}$, $0.5 \mathrm{mmol}, 1$ equiv.) after $15 \mathrm{~min}$. at $90{ }^{\circ} \mathrm{C}$, followed by a second reaction time of $15 \mathrm{~min}$. at $110{ }^{\circ} \mathrm{C}$ (for condensation step with $\mathbf{3 e}$ ), which gave $\mathbf{9 h}$ as a yellowish powder. $\mathrm{Mp}=245-256{ }^{\circ} \mathrm{C} .{ }^{1} \mathrm{H}-\mathrm{NMR}$

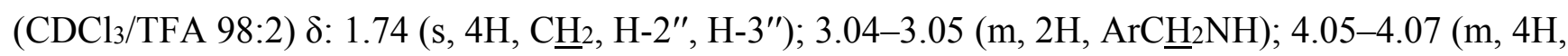

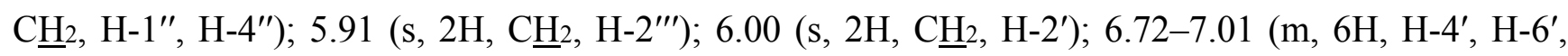

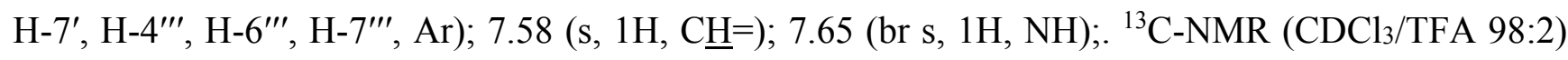

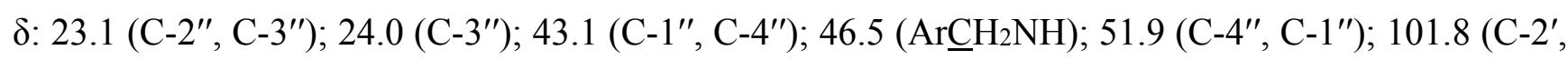
C-2"'); 102.2 (C-2'"', C-2'); 109.0 (C-6"'); 109.3 (C-6'); 109.4 (C-7"'); 109.8 (C-7'); 119.8 (C-5"'); $122.6(\underline{\mathrm{C}}=) ; 124.3\left(\mathrm{C}-4^{\prime \prime \prime}\right) ; 127.4\left(\mathrm{C}-4^{\prime}\right) ; 128.1\left(\mathrm{C}-5^{\prime}\right) ; 134.9(\underline{\mathrm{CH}}=)$; 148.6 (C-7'a); 148.9 (C-3'a); 149.2 (C-7"'a); 150.6 (C-3"'a); 168.9 ( $\underline{\mathrm{C}}=\mathrm{O}, \mathrm{C}-4) ; 193.0$ ( $\underline{\mathrm{C}}=\mathrm{S}, \mathrm{C}-2)$. HRMS, $m / z$ : 471.1048 found (calculated for $\mathrm{C}_{23} \mathrm{H}_{23} \mathrm{~N}_{2} \mathrm{O}_{5} \mathrm{~S}_{2}[\mathrm{M}+\mathrm{H}]^{+}$requires 471.1049). 
(5Z)3-[4-(1,3-Benzodioxol-5-ylmethylamino)butyl]-5-(2,3-dihydro-1,4-benzodioxin-6-ylmethylene)-2-

thioxo-1,3-thiazolidin-4-one (9i). According to the standard procedure, compound 9i was prepared in $59 \%$ yield $(143 \mathrm{mg})$ from $\mathrm{N}$-1-benzo[1,3]dioxol-5-ylmethyl-butane-1,4-diamine hydrochloride $6 \mathbf{e}$ (129.4 mg, $0.5 \mathrm{mmol}, 1$ equiv.), triethylamine (135 $\mu \mathrm{L}, 101 \mathrm{mg} ., 1 \mathrm{mmol}, 2$ equiv.) and 2,3-dihydro1,4-benzodioxin-6-carboxaldehyde $3 \mathbf{f}\left(82.1 \mathrm{mg}, 0.5 \mathrm{mmol}, 1\right.$ equiv.) after $15 \mathrm{~min}$. at $90{ }^{\circ} \mathrm{C}$, followed by a second reaction time of $15 \mathrm{~min}$. at $110^{\circ} \mathrm{C}$ (for condensation step with $3 \mathbf{f}$ ), which gave $9 \mathbf{i}$ as a yellowish powder. $\mathrm{Mp}=253-257{ }^{\circ} \mathrm{C} .{ }^{1} \mathrm{H}-\mathrm{NMR}\left(\mathrm{CDCl}_{3} / \mathrm{TFA} 98: 2\right) \delta$ : $1.68\left(\mathrm{~s}, 4 \mathrm{H}, \mathrm{CH}_{2}, \mathrm{H}-2^{\prime \prime}, \mathrm{H}-3^{\prime \prime}\right)$;

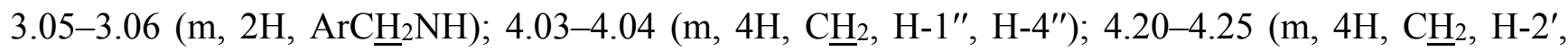
H-3'); 5.89 (s, 2H, C$\left.\underline{H}_{2}, \mathrm{H}-2^{\prime \prime \prime}\right)$; 6.70 (s, 3H, H-4"', H-6"', H-7'"', Ar); 6.85-6.96 (m, 3H, H-5', H-7', $\left.\mathrm{H}-8^{\prime}, \mathrm{Ar}\right) ; 7.50$ (br s, 1H, NH); 7.55 (s, 1H, $\left.\underline{\mathrm{H}}=\right)$. ${ }^{13} \mathrm{C}-\mathrm{NMR}\left(\mathrm{CDCl}_{3} / \mathrm{TFA} 98: 2\right) \delta: 23.1$ (C-2", C-3"); 23.8 (C-3", C-2"); 43.1 (C-1", C-4"); $47.0\left(\mathrm{Ar}_{\underline{C}}{ }_{2} \mathrm{NH}\right) ; 52.4$ (C4", C-1"); 64.2 (C-2', C-3'); 64.8 (C-3',

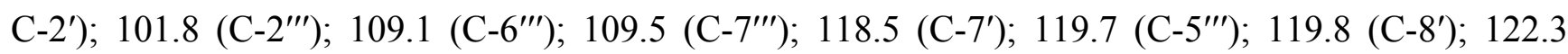
$(\underline{\mathrm{C}}=) ; 124.1\left(\mathrm{C}-4^{\prime \prime \prime}\right) ; 125.9\left(\mathrm{C}-5^{\prime}\right) ; 126.6\left(\mathrm{C}-6^{\prime}\right) ; 135.5(\underline{\mathrm{CH}}=) ; 144.0\left(\mathrm{C}-7^{\prime \prime \prime} \mathrm{a}\right) ; 146.9$ (C-3"'”a); 148.6 (C-8'a); 149.4 (C-4'a); 169.5 ( $\underline{\mathrm{C}}=\mathrm{O}, \mathrm{C}-4) ; 193.2$ ( $\underline{\mathrm{C}}=\mathrm{S}, \mathrm{C}-2)$. HRMS, $m / z$ : 485.1205 found (calculated for $\mathrm{C}_{24} \mathrm{H}_{25} \mathrm{~N}_{2} \mathrm{O}_{5} \mathrm{~S}_{2}[\mathrm{M}+\mathrm{H}]^{+}$requires 485.1203$)$.

(5Z)3-[4-(1,3-Benzodioxol-5-ylmethylamino)butyl]-5-(4-hydroxy-benzylidene)-2-thioxo-1,3-thiazolidin-4one $(\mathbf{9 j})$. According to the standard procedure, compound $9 \mathbf{j}$ was prepared in $34 \%$ yield $(75.2 \mathrm{mg}$ ) from $\mathrm{N}$-1-benzo[1,3]dioxol-5-ylmethyl-butane-1,4-diamine hydrochloride 6e (129.4 mg, $0.5 \mathrm{mmol}, 1$ equiv.), triethylamine (135 $\mu \mathrm{L}, 101 \mathrm{mg}, 1 \mathrm{mmol}, 2$ equiv.) and 4-hydroxybenzaldehyde $\mathbf{3 h}(61.1 \mathrm{mg}, 0.5 \mathrm{mmol}$, 1 equiv.) after $15 \mathrm{~min}$. at $90{ }^{\circ} \mathrm{C}$, followed by a second reaction time of $15 \mathrm{~min}$. at $110{ }^{\circ} \mathrm{C}$ (for condensation step with 3h), which gave $9 \mathbf{i}$ as a orange powder. $\mathrm{Mp}=93-124{ }^{\circ} \mathrm{C}$ (decomposition). ${ }^{1} \mathrm{H}-\mathrm{NMR}$ $\left(\mathrm{CDCl}_{3} / \mathrm{TFA} 98: 2\right) \delta$ : 1.59-1.73 (m, 4H, $\left.\underline{\mathrm{H}}_{2}, \mathrm{H}-2^{\prime \prime}, \mathrm{H}-3 "\right)$; 3.01-3.13 (m, 2H, $\left.\mathrm{ArC}_{2} \mathrm{NH}\right) ; 4.00-4.05$ (m, 4H, CH $2, \mathrm{H}-1^{\prime \prime}, \mathrm{H}-4^{\prime \prime}$ ); 5.88 (s, 2H, $\underline{\mathrm{H}}_{2}, \mathrm{H}-2^{\prime \prime \prime}$ ); 6.66-6.69 (m, H-4"', H-6"', H-7"', Ar); 6.86 (dd, $\left.2 \mathrm{H}, J=8.7 \mathrm{~Hz}, \mathrm{H}-2^{\prime}, \mathrm{H}-6^{\prime}, \mathrm{Ar}\right) ; 7.32$ (dd, 2H, $J=8.7 \mathrm{~Hz}, \mathrm{H}-3^{\prime}, \mathrm{H}-5^{\prime}, \mathrm{Ar}$ ); 7.55 (br s, 1H, NH); 7.60 (s, 1H, $\underline{\mathrm{H}}=, 1 \mathrm{H}) .{ }^{13} \mathrm{C}-\mathrm{NMR}\left(\mathrm{CDCl}_{3} / \mathrm{TFA} 98: 2\right) \delta: 22.5$ (C-2", C-3"); 23.2 (C-3", C-2"); 42.5 (C-1", C-4"); $46.4\left(\mathrm{ArCH}_{2} \mathrm{NH}\right) ; 51.9$ (C-4", C-1"'); 101.2 (C-2'"'); 108.5 (C-6"'); 108.8 (C-7"'); 116.1 (C-2', C-6'); 118.6 (C-5"'); $121.7(\underline{\mathrm{C}}=)$; $123.4\left(\mathrm{C}-4^{\prime \prime \prime}\right) ; 125.6$ (C-1'); 132.9 (C-3', C-5'); $134.8(\underline{\mathrm{C}} \mathrm{H}=) ; 148.0$ (C-7"'a); 148.8 (C-3"'a); 157.6 (C-4'); 169.0 ( $\underline{\mathrm{C}}=\mathrm{O}, \mathrm{C}-4) ; 192.6$ ( $\underline{\mathrm{C}}=\mathrm{S}, \mathrm{C}-2)$. HRMS, m/z: 443.1099 found (calculated for $\mathrm{C}_{22} \mathrm{H}_{23} \mathrm{~N}_{2} \mathrm{O}_{4} \mathrm{~S}_{2}[\mathrm{M}+\mathrm{H}]^{+}$requires 443.1095).

(5Z) 3-[4-(1,3-Benzodioxol-5-ylmethylamino)butyl]-5-(4-hydroxy-3-methoxybenzylidene)-2-thioxo-1,3thiazolidin-4-one (9k). According to the standard procedure, compound 9k was prepared in $46 \%$ yield (109 mg) from $N$-1-benzo[1,3]dioxol-5-ylmethyl-butane-1,4-diamine hydrochloride 6e (129.4 mg, $0.5 \mathrm{mmol}, 1$ equiv.), triethylamine (202 $\mu \mathrm{L}, 152 \mathrm{mg}, 1.5 \mathrm{mmol}, 3$ equiv.) and 4-hydroxy-3methoxybenzaldehyde $\mathbf{3 g}$ (76.1 mg, $0.5 \mathrm{mmol}, 1$ equiv.) after $30 \mathrm{~min}$. at $90{ }^{\circ} \mathrm{C}$, followed by a second reaction time of $30 \mathrm{~min}$. at $110{ }^{\circ} \mathrm{C}$ (for condensation step with $\mathbf{3 g}$ ), which gave $9 \mathbf{k}$ as a red powder. $\mathrm{Mp}=200-203{ }^{\circ} \mathrm{C} .{ }^{1} \mathrm{H}-\mathrm{NMR}\left(\mathrm{CDCl}_{3} / \mathrm{TFA} 98: 2\right) \delta: 1.71$ (s, 4H, CH$\left., \mathrm{H}-2^{\prime \prime}, \mathrm{H}-3{ }^{\prime \prime}\right) ; 3.05-3.06$ (m, 2H, $\mathrm{ArC}_{2} \mathrm{NH}$ ); 3.88 (s, 3H, OC$\left.\underline{H}_{3}\right) ; 4.04$ (s, 4H, $\left.\underline{\mathrm{H}}_{2}, \mathrm{H}-1^{\prime \prime}, \mathrm{H}-4^{\prime \prime}\right) ; 5.91$ (s, 2H, $\left.\underline{\mathrm{H}}_{2}, \mathrm{H}-2^{\prime \prime \prime}\right) ; 6.74$ (s, 3H, H-4"', H-6"', H-7'", Ar); 6.87-7.02 (m, 3H, H-2', H-5', H-6', Ar); 7.58 (s, 1H, C $\underline{H}=$ ); 7.65 (br s, 1H, $\mathrm{NH}) .{ }^{13} \mathrm{C}-\mathrm{NMR}\left(\mathrm{CDCl}_{3} / \mathrm{TFA}\right.$ 98:2) $\delta: 23.1$ (C-2", C-3"); 23.9 (C-3", C-2"); 42.9 (C-1", C-4"); $46.6\left(\mathrm{ArCH}_{2} \mathrm{NH}\right) ; 52.1$ (C-4", C-1"'); $56.1\left(\mathrm{OC}_{3}\right) ; 101.8$ (C-2"'); 109.0 (C-6"' $) ; 109.6$ (C-7"'); 112.3 
$\left(\mathrm{C}-6^{\prime}\right) ; 115.5\left(\mathrm{C}-2^{\prime}\right) ; 119.1\left(\mathrm{C}-5^{\prime \prime \prime}\right) ; 122.7(\underline{\mathrm{C}}=) ; 124.0\left(\mathrm{C}-5^{\prime}\right) ; 125.8\left(\mathrm{C}-1^{\prime}\right) ; 126.5\left(\mathrm{C}-4^{\prime \prime \prime}\right) ; 134.9(\underline{\mathrm{C}} \mathrm{H}=)$; 147.1 (C-3'); 148.6 (C-7'"'a); 148.8 (C-4'); 149.2 (C-3'"'a); 168.5 ( $\underline{\mathrm{C}}=\mathrm{O}, \mathrm{C}-4) ; 193.2$ ( $\underline{\mathrm{C}}=\mathrm{S}$, C-2). HRMS, $m / z$ : 473.1205 found (calculated for $\mathrm{C}_{23} \mathrm{H}_{25} \mathrm{~N}_{2} \mathrm{O}_{5} \mathrm{~S}_{2}[\mathrm{M}+\mathrm{H}]^{+}$requires 473.1206).

(5Z)3-[4-(2,3-Dihydro-benzo[1,4] dioxin-6-ylmethylamino)butyl]-5-(1,3-benzodioxol-5-ylmethylene)-2thioxo-1,3-thiazolidin-4-one (91). According to the standard procedure, compound 91 was prepared in $15 \%$ yield (36.3 $\mathrm{mg})$ from $N$-1-(2,3-dihydro-benzo[1,4]dioxin-6-ylmethyl)-butane-1,4-diamine hydrochloride $6 \mathbf{f}$ ( $136.4 \mathrm{mg}, 0.5 \mathrm{mmol}, 1$ equiv.), triethylamine ( $202 \mu \mathrm{L}, 152 \mathrm{mg}, 1.5 \mathrm{mmol}, 3$ equiv.) and piperonaldehyde $3 \mathrm{e}\left(75.1 \mathrm{mg}, 0.5 \mathrm{mmol}, 1\right.$ equiv.) after $15 \mathrm{~min}$. at $90{ }^{\circ} \mathrm{C}$, followed by a second reaction time of $15 \mathrm{~min}$. at $110{ }^{\circ} \mathrm{C}$ (for condensation step with $\mathbf{3 e}$ ), which gave 91 as a yellowish powder. $\mathrm{Mp}=172-233{ }^{\circ} \mathrm{C}$ (decomposition). ${ }^{1} \mathrm{H}-\mathrm{NMR}\left(\mathrm{CDCl}_{3} / \mathrm{TFA} 98: 2\right) \delta: 1.66-1.69$ (m, 4H, $\underline{\mathrm{C}}_{2}$, H-2", H-3"); 3.03-3.10 (m, 2H, ArC并 $2 \mathrm{NH}$ ); 4.03-4.07 (m, 4H, CH2, H-1", H-4"'); 4.16-4.19 (m, 4H,

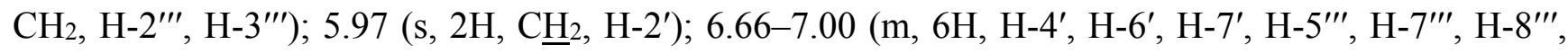
Ar); 7.55 (br s, 1H, NH); 7.59 (s, 1H, $\underline{\mathrm{H}}=$ ). ${ }^{13} \mathrm{C}-\mathrm{NMR}\left(\mathrm{CDCl}_{3} / \mathrm{TFA}\right.$ 98:2) $\delta: 23.8$ (C-2", C-3"); 24.2 (C-3"); 43.1 (C-1", C-4"); $47.0\left(\mathrm{Ar}_{-} \mathrm{H}_{2} \mathrm{NH}\right) ; 52.1$ (C-4", C-1"); 64.2 (C-2"'); 64.4 (C-3"'); 102.2

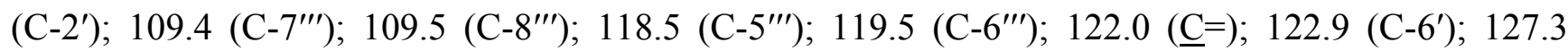

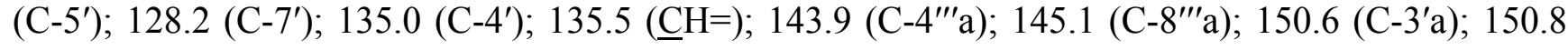
$(\mathrm{C}-7$ 'a); $168.5(\underline{\mathrm{C}}=\mathrm{O}, \mathrm{C}-4) ; 193.0 \quad(\underline{\mathrm{C}}=\mathrm{S}, \mathrm{C}-2) . \mathrm{HRMS}, m / z: 485.1205$ found (calculated for $\mathrm{C}_{24} \mathrm{H}_{25} \mathrm{~N}_{2} \mathrm{O}_{5} \mathrm{~S}_{2}[\mathrm{M}+\mathrm{H}]^{+}$requires 485.1206).

(5Z)3-[4-(2,3-Dihydro-benzo[1,4]dioxin-6-ylmethylamino)butyl]-5-(2,3-dihydro-benzo[1,4]dioxin-6ylmethylene)-2-thioxo-1,3-thiazolidin-4-one $(\mathbf{9 m})$. According to the standard procedure, compound $9 \mathrm{~m}$ was prepared in 7\% yield $(17.5 \mathrm{mg})$ from $\mathrm{N}$-1-(2,3-dihydro-benzo[1,4]dioxin-6-ylmethyl)-butane-1,4diamine hydrochloride $6 \mathbf{f}(136.4 \mathrm{mg}, 0.5 \mathrm{mmol}, 1$ equiv.), triethylamine (202 $\mu \mathrm{L}, 152 \mathrm{mg}, 1.5 \mathrm{mmol}, 3$ equiv.) and 2,3-dihydro-1,4-benzodioxin-6-carboxaldehyde $\mathbf{3 f}(82.1 \mathrm{mg}, 0.5 \mathrm{mmol}, 1$ equiv.) after 15 min. at $90{ }^{\circ} \mathrm{C}$, followed by a second reaction time of $15 \mathrm{~min}$. at $110^{\circ} \mathrm{C}$ (for condensation step with 3f), which gave $9 \mathrm{~m}$ as a yellowish powder. $\mathrm{Mp}=170-243{ }^{\circ} \mathrm{C}$ (decomposition). ${ }^{1} \mathrm{H}-\mathrm{NMR}\left(\mathrm{CDCl}_{3} / \mathrm{TFA}\right.$

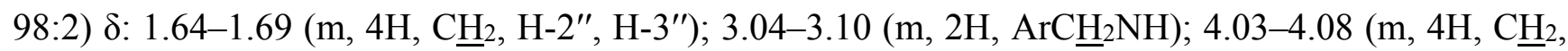

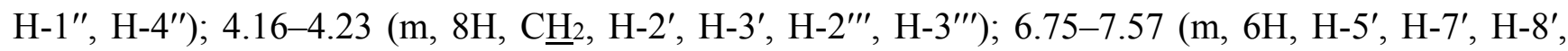
H-5"', H-7"', H-8"', Ar); 7.60 (br s, 1H, NH); 8.77 (s, 1H, Cㅍ=). ${ }^{13} \mathrm{C}-\mathrm{NMR}$ (CDCl $3 / \mathrm{TFA}$ 98:2) $\delta: 24.2$ (C-2", C-3"'); 44.0 (C-1", C-4"); 64.2 (C-2', C-2'"'); 64.8 (C-3', C-3"'); 118.4 (C-7', C-7"'); 119.6 (C-8',

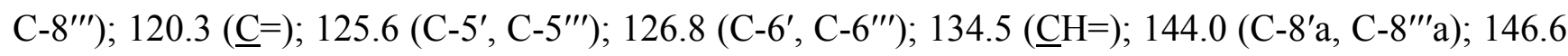
(C-4'a, C-4"'a); 166.6 ( $\underline{\mathrm{C}}=\mathrm{O}, \mathrm{C}-4) ; 182.5$ ( $\underline{\mathrm{C}}=\mathrm{S}, \mathrm{C}-2)$. HRMS, $m / z: 499.1364$ found (calculated for $\mathrm{C}_{25} \mathrm{H}_{27} \mathrm{~N}_{2} \mathrm{O}_{5} \mathrm{~S}_{2}[\mathrm{M}+\mathrm{H}]^{+}$requires 499.1366$)$.

(5Z)3-[4-(2,3-Dihydro-benzo[1,4] dioxin-6-ylmethylamino)butyl]-5-(4-hydroxy-3-methoxybenzylidene)-2thioxo-1,3-thiazolidin-4-one (9n). According to the standard procedure, compound 9n was prepared in 34\% yield $(82.7 \mathrm{mg}$ ) from $\mathrm{N}$-1-(2,3-dihydro-benzo[1,4]dioxin-6-ylmethyl)-butane-1,4-diamine hydrochloride $\mathbf{6 f}$ (136.4 mg, $0.5 \mathrm{mmol}, 1$ equiv.), triethylamine (202 $\mu \mathrm{L}, 152 \mathrm{mg}, 1.5 \mathrm{mmol}, 3$ equiv.) and 4-hydroxy-3methoxybenzaldehyde $\mathbf{3 g}$ (76.1 mg, $0.5 \mathrm{mmol}, 1$ equiv.) after $30 \mathrm{~min}$. at $90{ }^{\circ} \mathrm{C}$, followed by a second reaction time of $30 \mathrm{~min}$. at $110{ }^{\circ} \mathrm{C}$ (for condensation step with $\mathbf{3 g}$ ), which gave $\mathbf{9 n}$ as a red powder.

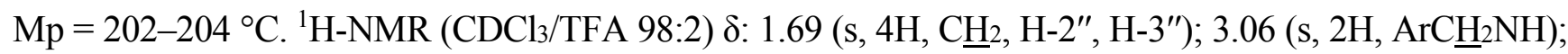


3.86 (s, 3H, OC$\left.\underline{H}_{3}\right) ; 4.03$ (s, 4H, $\left.\underline{\mathrm{H}}_{2}, \mathrm{H}-1^{\prime \prime}, \mathrm{H}-4^{\prime \prime}\right) ; 4.16$ (s, 4H, $\left.\underline{\mathrm{H}}_{2}, \mathrm{H}-2^{\prime \prime \prime}, \mathrm{H}-3^{\prime \prime \prime}\right)$; 6.67-7.03 (m, 6H,

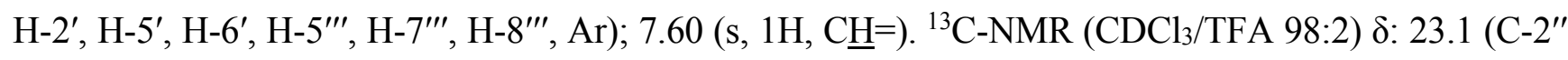
or $\left.3^{\prime \prime}\right) ; 23.8$ (C-3" ou C-2"); $43.1\left(\mathrm{C}-1^{\prime \prime}\right.$ ou 4"); $47.0\left(\operatorname{ArCH}_{2} \mathrm{NH}\right) ; 52.1$ (C-4", C-1"); $56.1\left(\mathrm{OCH}_{3}\right)$; 64.4 (C-2"', C-3"'); 64.4 (C-3"', C-2'"'); 112.6 (C-6'); 115.6 (C-2'); 118.4 (C-7'"'); 118.6 (C-8"''); 119.0 $\left(\mathrm{C}-6^{\prime \prime \prime}\right) ; 122.0(\underline{\mathrm{C}}=) ; 122.9$ (C-5'"); $125.9\left(\mathrm{C}-1^{\prime}\right) ; 126.8$ (C-5'); $135.9(\underline{\mathrm{CH}}=) ; 143.9$ (C-8'"'a); 145.1 (C-3'a); 147.2 (C-4'"'a); 148.9 (C-4');169.4 ( $\underline{\mathrm{C}}=\mathrm{O}, \mathrm{C}-4) ; 193.1$ ( $\underline{\mathrm{C}}=\mathrm{S}, \mathrm{C}-2)$. HRMS, $m / z$ : 487.1361 found (calculated for $\mathrm{C}_{24} \mathrm{H}_{27} \mathrm{~N}_{2} \mathrm{O}_{5} \mathrm{~S}_{2}[\mathrm{M}+\mathrm{H}]^{+}$requires 487.1359).

\subsection{Biochemistry Section}

\subsubsection{Protein Kinase Assay Buffers}

Buffer $A$ : $10 \mathrm{mM} \mathrm{MgCl} 2,1 \mathrm{mM}$ EGTA, $1 \mathrm{mM}$ DTT, $25 \mathrm{mM}$ Tris-HCl pH 7.5, $50 \mu \mathrm{g}$ heparin/mL.

Buffer B: $60 \mathrm{mM} \beta$-glycerophosphate, $15 \mathrm{mM}$ p-nitrophenyl-phosphate, $25 \mathrm{mM}$ Mops (pH 7.2), $5 \mathrm{mM}$ EGTA, $15 \mathrm{mM} \mathrm{MgCl} 2,1 \mathrm{mM}$ DTT, $1 \mathrm{mM}$ sodium vanadate, $1 \mathrm{mM}$ phenylphosphate.

\subsubsection{Kinase Preparations and Assays}

Kinase activities for each enzyme were assayed in buffer A (25 mM Tris- $\mathrm{HCl} \mathrm{pH} 7.5,10 \mathrm{mM} \mathrm{MgCl}$, $1 \mathrm{mM}$ EGTA, $1 \mathrm{mM}$ DTT, $50 \mu \mathrm{g} / \mathrm{mL}$ Heparin, BSA $0.15 \mathrm{mg} / \mathrm{mL}$ ) or B (60 mM $\beta$-glycerophosphate, $30 \mathrm{mM}$ p-Nitrophenylphosphate, $25 \mathrm{mM}$ MOPS, $5 \mathrm{mM}$ EGTA, $15 \mathrm{mM} \mathrm{MgCl} 2,1 \mathrm{mM}$ DTT, $0.1 \mathrm{mM} \mathrm{Na}$ vanadate), with their corresponding substrates, in the presence of $15 \mu \mathrm{M}\left[\gamma_{-}{ }^{33} \mathrm{P}\right]$ ATP $(3000 \mathrm{Ci} / \mathrm{mmol}$; $10 \mathrm{mCi} / \mathrm{mL}$ ) in a final volume of $30 \mu \mathrm{L}$. After $30 \mathrm{~min}$ incubation at $30^{\circ} \mathrm{C}$, the reaction was stopped by harvesting, using a FilterMate harvester (Packard, Meriden, CT, USA), onto P81 phosphocellulose papers (GE Healthcare, Velizy-Villacoublay, France) which were washed in 1\% phosphoric acid. Scintillation fluid was added and the radioactivity measured in a Packard counter. Blank values were subtracted and activities calculated as pmoles of phosphate incorporated during the 30 min incubation. The activities were expressed in a percentage of the maximal activity, i.e., in the absence of inhibitors. Controls were performed with appropriate dilutions of DMSO. CK1 and Haspin peptide substrates were obtained from Proteogenix (Oberhausbergen, France).

$C D K 5 / p 25$ (human, recombinant) was prepared as previously described [31]. Its kinase activity was assayed in buffer B, with $1 \mathrm{mg}$ histone $\mathrm{H} 1 / \mathrm{mL}$.

Casein kinase $1(C K 1 \delta / \varepsilon)$ (porcine brain, native) was assayed with $0.67 \mu \mathrm{g}$ of CKS peptide (RRKHAAIGpSAYSITA) [32].

$G S K-3 \alpha / \beta$ (porcine brain, native) was assayed, as described for CDK5/p25 but in Buffer A and using a GSK-3 specific substrate (GS-1: YRRAAVPPSPSLSRHSSPHQSpEDEEE) (pS stands for phosphorylated serine) [33]. GS-1 was synthesized by Millegen (Labege, France).

Haspin kinase domain (HsHaspin-kd aa 470 to 798) encoding cDNA, obtain by RT-PCR, was cloned into pGex-6P-3. The fusion protein was expressed in Escherichia coli strain BL21-KRX (Promega, Madison, WI, USA) and purified by affinity chromatography on glutathione-agarose beads (Sigma). Haspin-kd activity was assayed with $3 \mu \mathrm{M}$ Histone H3 (1-21) peptide, a specific Haspin substrate, (ARTKQTARKSTGGKAPRKQLA), in Buffer H (MOPS $25 \mathrm{mM} \mathrm{pH} \mathrm{7.5;} 10 \mathrm{mM} \mathrm{MgCl}_{2}$ ). 


\subsection{Cell Culture and Survival Assays}

Skin diploid fibroblastic cells were provided by BIOPREDIC International Company (Rennes, France). Caco2 (Ref ECACC: 86010202), Huh-7D12 (Ref ECACC: 01042712), MDA-MB-231 (Ref ECACC: 92020424), HCT-116 (Ref ECACC: 91091005), PC3 (Ref ECACC: 90112714), NCI-H727 (Ref ECACC: 94060303) cell lines were obtained from the ECACC collection and HaCaT (from Cell Lines Service, Eppelheim, Germany). Cells were grown according to ECACC recommendations [34]. The toxicity test of the compounds on these cells was as follows: $2 \times 10^{3}$ cells for HCT-116 cells or $4 \times 10^{3}$ for the other cells were seeded in 96 multiwell plates in triplicate and left for $24 \mathrm{~h}$ for attachment, spreading and growing. Then, cells were exposed for $48 \mathrm{~h}$ to increasing concentrations of the compounds, ranging from 0.1 to $25 \mu \mathrm{M}$ in a final volume of $120 \mu \mathrm{L}$ of culture medium. Cells were fixed in cooled solution of $90 \%$ ethanol $/ 5 \%$ acetic acid, nuclei were stained with Hoechst 3342 (Sigma) and counted using automated imaging analysis (Cellomics Arrayscan VTI/HCS Reader, Thermo/Scientific, Waltham, MA, USA). The IC50 were graphically determined.

\section{Conclusions}

In summary, we have developed, in this preliminary project, a new route to (5Z) 3-(4-arylmethylamino) butyl-5-arylidene-2-thioxo-1,3-thiazolidine-4-ones 9. Starting from commercial butane-1,4-diamine, the process involved six steps and the key step is a solution phase "one-pot two-steps" approach for the construction of the 2-thioxo-1,3-thiazolidine-4-one platform under microwave dielectric heating followed by Knoevenagel condensation for installation of the 5-arylidene moiety as second point of diversity. This methodology offered the possibility of preparing a library of fourteen new compounds in moderate to good yields and, the targeted compounds $9 \mathbf{9}-\mathbf{n}$ have been built with a Z-geometry. The in vitro inhibition of cell proliferation was carried out on a panel of seven representative tumoral cell lines and the compounds 9a-n were also evaluated against four protein kinases. Among all of these compounds, the compound $9 \mathbf{j}$ turned out to be interesting because it presented selective micromolar inhibition activity on $S_{s} \mathrm{CK} 1\left(\mathrm{IC}_{50} 1.4 \mu \mathrm{M}\right)$. Molecules $9 \mathbf{h}$ and $9 \mathbf{i}$ were also bioactive on $S_{s} \mathrm{CK} 1$ and $H_{s} \mathrm{CDK} 5$-p25. The current results are the starting point of a new larger program within our group to investigate intensively the biological properties of these new inhibitors with potential application in Alzheimer's disease or in cancer.

\section{Acknowledgments}

Two of us (C.D.D. and C.N.A.) wish to thank the "Benian International Fondation", "ElecBTP" and the "Ministère de l'Enseignement Supérieur et de la Recherche de la Côte d'Ivoire" for their respective grants. Financial support of this program carried out under the French National Cancer Institute “Cancéropôle Grand Ouest" by contract "Ion Channel-Network CGO 2012", is gratefully acknowledged.

\section{Author Contributions}

J.-P.B. was the manager of the project. J.-P.B., Y.-A.B. and J.M. conceived and designed the experiments. C.D.D., C.N.A. and W.-K.C. performed the chemical experiments. A.D. and B.B. performed the kinase assays. S.B. and S.R. analyzed the data of kinase assays. M.R. and R.L.G. performed the 
antiproliferative activity assays. R.L.G. and A.C. analyzed the data of antiproliferative assays and J.-P.B. wrote the paper.

\section{Conflicts of Interest}

The authors declare no conflict of interest.

\section{References}

1. Mentgen, T.; Steuer, C.; Klein, C.D. Privileged scaffolds or promiscuous binders: A comparative study on rhodanines and related heterocycles in medicinal chemistry. J. Med. Chem. 2012, 55, 743-753.

2. Masic, L.P.; Tomasic, T. Rhodanine as a privileged scaffold in drug discovery. Curr. Med. Chem. 2009, 16, 1596-1629.

3. Maga, G.; Falchi, F.; Garbelli, A.; Belfiore, A.; Witvrow, M.; Manetti, F.; Botta, M. Pharmacophore modeling and molecular docking led to the discovery of inhibitors of human immunodeficiency virus-1. Replication targeting the human cellular aspartic acid-glutamic acid-alanine-aspartic acid box polypeptide 3. J. Med. Chem. 2008, 51, 6635-6638.

4. Cutshall, N.S.; O’Day, C.; Prezhdo, M. Rhodanine derivatives as inhibitors of JSP-1. Bioorg. Med. Chem. Lett. 2005, 15, 3374-3382.

5. El-Kabbani, M.; Ruiz, F.; Darmanim, C.; Chung, R.P.T. Aldose reductase structures: Implications for mechanism and inhibition, Cell. Mol. Life Sci. 2004, 61, 750-752.

6. Summerer, D.; Rudinger, N.Z.; Ilka Detmer, I.; Marx, A. Enhanced Fidelity in Mismatch Extension by DNA Polymerase through Directed Combinatorial Enzyme Design. Angew. Chem. Int. Ed. 2005, 44, 4712-4715.

7. Tomašić, T.; Zidar, N.; Šink, R.; Kovač, A.; Blanot, D.; Contreras-Martel, C.; Dessen, A.; Müller-Premru, M.; Zega, A.; Gobec, S.; et al. Structure-Based Design of a New Series of D-Glutamic Acid Based Inhibitors of Bacterial UDP- $N$-acetylmuramoyl-l-alanine: D-Glutamate Ligase (MurD). J. Med. Chem. 2011, 54, 4600-4610.

8. Rinaldi, M.; Tintori, C.; Franchi, L.; Vignaroli, G.; Innitzer, A.; Massa, S.; Esté, J.A.; Gonzalo, E.; Christ, F.; Debyser, Z.; et al. A Versatile and Practical Synthesis toward the Development of Novel HIV-1 Integrase Inhibitors. Chem. Med. Chem. 2011, 6, 343-352.

9. Jadav, S.S.; Sinha, B.N.; Hilgenfeld, R.; Pastorino, B.; de Lamballerie, X.; Jayaprakash, V. Thiazolidone derivatives as inhibitors of chikungunya virus. Eur. J. Med. Chem. 2015, 89, 172-178.

10. Bulic, B.; Pickhardt, M.; Schmidt, B.; Mandelkow, E.M.; Waldmann, H.; Mandelkow, E. Development of Tau Aggregation Inhibitors for Alzheimer's Disease. Angew. Chem. Int. Ed. 2009, 48, 1740-1752.

11. Bulic, B.; Pickhardt, M.; Schmidt, B.; Mandelkow, E.M. Tau protein and tau aggregation inhibitors. Neuropharmacology 2010, 59, 276-289.

12. Strittmatter, T.; Bareth, B.; Immel, T.A.; Huhn, T.; Mayer, T.U.; Marx, A. Small Molecule Inhibitors of Human DNA Polymerase $\lambda$. Chem. Biol. 2011, 6, 314-319.

13. Fedorov, O.; Müller, S.; Knapp, S. The (un)targeted cancer kinome. Nat. Chem. Biol. 2010, 6, 166-169. 
14. Bazureau, J.P.; Carreaux, F.; Renault, S.; Meijer, L.; Lozach, O. Imidazolone derivatives, preparation method thereof and biological use of same. Patent WO 2009/05032 A2, 23 April 2009.

15. Debdab, M.; Carreaux, F.; Renault, S.; Soundararajan, M.; Fedorov, O.; Filippakopoulos, P.; Lozach, O.; Babault, L.; Tahtouh, T.; Baratte, B.; et al. Design, synthesis and biological evaluation of leucettines, a class of potent CLK and DYRK kinases inhibitors derived from the marine sponge leucettamine B. Modulation of alternative RNA splicing. J. Med. Chem. 2011, 54, 4172-4186.

16. Tahtouh, T.; Elkins, J.M.; Filippakopoulos, P.; Soundararajan, M.; Burgy, G.; Durieu, E.; Cochet, C.; Schmid, R.S.; Lo, D.C.; Delhommel, F.; et al. Selectivity, cocrystal structures, and neuroprotective properties of Leucettines, a family of protein kinase inhibitors derived from the marine sponge alkaloid Leucettamine B. J. Med. Chem. 2012, 55, 9312-9330.

17. Smith, B.; Medda, F.; Gokhale, V.; Dunckley, T.; Hulme, C. Recent Advances in the Design, Synthesis, and Biological Evaluation of Selective DYRK1A Inhibitors: A New Avenue for a Disease Modifying Treatment of Alzheimer's? ACS Chem. Neurosci. 2012, 11, 857-872.

18. Ionescu, A.; Dufrasne, F.; Gelbcke, M.; Jabin, I.; Kiss, R.; Lamoral-Theys, D. DYRK1A Kinase inhibitors with emphasis on cancer. Mini-Rev. Med. Chem. 2012, 12, 1315-1329.

19. Xiao, Y.A.; Wang, Z.Q.; Wang, X.M.; Hui, Y.; Ling, Y.; Wang, X.Y.; He, L.Q. Synthesis and in-vitro biological evaluation of novel 2-aminoimidazolinone derivatives as anti-tumor agents. Chin. Chem. Lett. 2013, 24, 727-730.

20. Ling, Y.; Wang, Z.Q.; Xiao, Y.A.; Zhu, C.; Shen, L.; Wang, X.M.; Hui, Y.; Wang, X.Y. Benzylidene 2-aminoimidazolones derivatives: Synthesis and in vitro evaluation of anti-tumor carcinoma activity. Chem. Pharm. Bull. 2013, 61, 1081-1084.

21. Coulibaly, W.K.; Paquin, L.; Bénie, A.; Bekro, Y.A.; Durieu, E.; Meijer, L.; Bazureau, J.P. Synthesis of $N, N^{\prime}$-bis(5-arylidene-4-oxo-3,5-dihydro-4H-imidazol-2-yl)diamines bearing various linkers and biological evaluation as potential inhibitors of kinases. Eur. J. Med. Chem. 2012, 58, 581-590.

22. Coulibaly, W.K.; Paquin, L.; Bénie, A.; Bekro, Y.A.; Durieux, E.; Rucheau, S.; Meijer, L.; le Guével, R.; Corlu, A.; Bazureau, J.P. Synthesis of new N,N'-bis(5-arylidene-4-oxo-4,5-dihydrothiazolidine-2-yl)piperazine derivatives under microwave irradiation and preliminary biological evaluation. Sci. Pharm. 2012, 80, 825-836.

23. Coulibaly, W.K.; Paquin, L.; Bénie, A.; Bekro, Y.A.; le Guével, R.; Ravache, M.; Corlu, A.; Bazureau, J.P. Prospective directed to the synthesis of unsymmetrical linked bis-5-arylidene rhodanine derivatives via "one-pot two steps" reactions under microwave irradiation with their antitumor activity. Med. Chem. Res. 2015, 24, 1653-1661.

24. Bazureau, J.P.; Paquin, L.; L’Helgoual'ch, J.M.; Carrie, D.; Limanton, E.; Guihéneuf, S.; Burgy, G.; Coulibaly, W.K.; Komaty, S. Microwaves in Heterocyclic Chemistry. In Microwaves in Organic Synthesis, 3rd ed.; Loupy, A., de la Hoz, A., Eds.; Wiley-VCH: Weinheim, Germany, 2012; Chapter 14, pp 673-766.

25. Raj, R.; Mehra, V.; Gut, J.; Rosenthal, P.J.; Wicht, K.J.; Egan, T.J.; Hopper, M.; Wrischnik, L.A.; Land, K.M.; Kumar, V. Discovery of highly selective 7-chloroquinoline-thiohydantoins with potent antimalarial activity. Eur. J. Med. Chem. 2014, 84, 425-432.

26. Bonger, K.M.; Hoogendoorn, S.; van Koppen, C.J.; Timmers, C.M.; Overkleeft, H.S.; van der Marel, G.A. Synthesis and pharmacological evaluation of dimeric follicle-stimulating hormone receptor antagonists. ChemMedChem 2009, 4, 2098-2102. 
27. Krstenansky, J.L.; Cotteril, I. Recent advances in microwave-assisted organic syntheses. Curr. Opin. Drug. Discov. Dev. 2000, 3, 454-461.

28. Guihéneuf, S.; Paquin, L.; Carreaux, F.; Durieu, É.; Bénédetti, H.; Le Guével, R.; Corlu, A.; Meijer, L.; Bazureau, J.P. Microwave Assisted Organic Synthesis (Maos) of New Dispacamide a Derivatives Bearing a Thiazolinone Platform, Biological Assays on Inhibition of Protein Kinases and Cell Effects. Curr. Microw. Chem. 2014, 1, 33-40.

29. Xia, Z.; Knaak, C.; Ma, J.; Beharry, Z.M.; Mc Innes, C.; Wang, W.; Kraft, A.S.; Smith, C.D. Synthesis and evaluation of novel inhibitors of Pim-1 and Pim-2 protein kinases. J. Med. Chem. 2009, 52, 74-86.

30. Dai, J.; Sultan, S.; Taylor, S.S.; Higgins, J.M. The kinase haspin is required for mitotic histone H3 Thr 3 phosphorylation and normal metaphase chromosome alignment. Genes Dev. 2005, 19, 472-488.

31. Leclerc, S.; Garnier, M.; Hoessel, R.; Marko, D.; Bibb, J.A.; Snyder, G.L.; Greengard, P.; Biernat, J.; Mandelkow, E.M.; Eisenbrand, G.; et al. Indirubins inhibit glycogen synthase kinase-3 beta and CDK5/p25, two protein kinases involved in abnormal tau phosphorylation in Alzheimer's disease. A property common to most cyclin-dependent kinase inhibitors? J. Biol. Chem. 2001, 276, 251-260.

32. Reinhardt, J.; Ferandin, Y.; Meijer, L. Purification CK1 by affinity chromatography on immobilised axin. Protein Expr. Purif. 2007, 54, 101-109.

33. Primot, A.; Baratte, B.; Gompel, M.; Borgne, A.; Liabeuf, S.; Romette, J.L.; Costantini, F.; Meijer, L. Purification of GSK-3 by affinity chromatography on immobilised axin. Protein Exp. Purif. 2000, 20, 394-404.

34. Nakabayashi, H.; Taketssa, K.; Miyano, K.; Yamane, T.; Sato, J. Growth of human hepatoma cell lines with differentiated functions in chemically defined medium. Cancer Res. 1982, 42, 3858-3863.

Sample Availability: Samples of the compounds $\mathbf{9 a}-\mathbf{n}$ are available from the authors.

(C) 2015 by the authors; licensee MDPI, Basel, Switzerland. This article is an open access article distributed under the terms and conditions of the Creative Commons Attribution license (http://creativecommons.org/licenses/by/4.0/). 